DEPARTMENT OF ECONOMICS WORKING PAPER SERIES

\title{
India's structural transformation and role in the world economy
}

\author{
Codrina Rada \\ Rüdiger von Arnim
}

Working Paper No: 2012-05

June 2012

\author{
University of Utah \\ Department of Economics \\ 260 S. Central Campus Dr., Rm. 343 \\ Tel: (801) 581-7481 \\ Fax: (801) 585-5649 \\ http://www.econ.utah.edu
}




\title{
India's structural transformation and role in the world economy
}

\author{
Codrina Rada \\ University of Utah \\ e-mail: rada@economics.utah.edu \\ Rüdiger von Arnim \\ University of Utah \\ e-mail: rudiger.vonarnim@economics.utah.edu
}

\begin{abstract}
This paper employs (1) a three-sector structuralist model of development with informal and formal activities and (2) a global one-sector model with demand determined outputs and bargained distribution to investigate whether India's growth performance can be sustained, where the country might face constraints to growth, and how India's growth matters in the global economy.
\end{abstract}

Keywords: structural change; informal sector; India; global demand. JEL Classification: O11, O17, O53, F01.

Acknowledgements: This paper was prepared as a background paper for UNCTAD. Financial support is gratefully acknowledged. The global model applied here was developed for a study for International Institute of Labour Studies (IILS). Financial support is gratefully acknowledged. 


\section{Introduction}

Four years ago the collapse of Lehman Brothers has set off the most severe global financial crisis since the Great Depression. Developed economies slid into a deep recession and policy makers took over the reigns of their economies. Today, recovery in the industrialized world remains fragile, and divergence within the club of rich countries is becoming the rule: Europe remains in disarray while the US and until recently, Japan, show sign of steady, albeit tepid growth. What is different about this global crisis is that, so far, a significant share of the developing world has avoided a prolonged economic collapse. A growing amount of research points to the resilience of developing economies_especially China, India and Brazil—and even suggests that a decoupling of the South from the North is underway.

India, next to China, is touted as a potential source of regional economic growth and demand. While some of this optimism is warranted, a closer look at its performance in several dimensions is necessary in order to assess its chances for sustainable growth and development. Specifically, we address a) India's structural transformation and b) its regional and global linkages. The importance of each of these aspects and our approach to analyzing them are as follows:

On structural transformation: Sustainable growth and development requires a continuous transformation of the economy towards higher value-added sectors and activities that produce income elastic goods, have an advantage in terms of dynamic economies of scale, create interand intra-sectoral linkages and provide incentives for innovation and learning. Industries in general and manufacturing in particular are the sectors that historically meet these criteria. More recently, progress in information and computing technology has advanced some services to the status of dynamic sectors. While these sectors are the core components of an economy's engine of economic and productivity growth they are also very capital intensive. Hence, direct employment creation by high productivity sectors is limited. To avoid a sectoral enclave trap, policy coordination is necessary to promote and sustain linkages between high-productivity dynamic sectors and labor intensive sectors. Such policy approach is especially needed in an economy with a large and expanding labor force as that of India's.

The movement of labor from low to high productivity sectors generally aids growth through several channels. First, it acts through the demand channel-higher wages imply higher aggregate demand but also shifts in demand patterns towards goods with higher technological content, thus stimulating structural change and creating economy-wide benefits as discussed above. Second, it acts through a rise in overall productivity growth along the lines of Verdoorn-Kaldor. Third, it provides the means for human capital accumulation at the microeconomic level. Fourth, through income and demand channels combined it reduces the degree to which non-industrialized economies are dependent on the goods and financial markets of the North.

To explore these important aspects of development we employ a three-sector model for India to illustrate the differences between a 'high road' equilibrium, where growth is accompanied by structural change in terms of employment, and cumulative causation sustains it; and a 'low road' equilibrium where output growth is too weak in comparison to productivity to lead to labor transfer. In this latter case, growth but no structural change occurs. This jobless growth perpetuates underemployment and poverty which can stall development and eventually growth itself. 
On regional and global linkages: India has deepening ties with the global economy. Service activities especially have been crucial. A significant export surplus in this sector, however, has not been sufficiently large to create an external surplus. The deficit might be driven by the capital account. It is clear, however, that India as a motor of growth both globally and regionally plays a very different role than other countries. In this section, we investigate the regional trade structure and propagation of shocks, using a multi-country one sector model with demand determined output. The focus here shifts from India to the four oft-discussed BRICs: Brazil, Russia, India and China.

\section{Growth and structural transformation in India}

The Indian economy has followed the classical patterns of transformation towards secondary and tertiary sectors in terms of contribution to overall output but not so much in terms of employment. Despite impressive expansion in production, job creation in the formal or the organized sector has been less than extraordinary for the last two decades. India's workforce remains employed in relatively low-productivity, low-pay jobs even if organized activities output has expanded annually at an average rate of more than six per cent. Labor productivity in the organized sector grew only slightly slower, leaving little need for additional employment. ${ }^{1}$ By 2005, more than 90 per cent of India's labor force is in the unorganized sector. The implications of these patternsof development are many.

First, a widening gap between India's skilled and well-paid on the one hand and those unskilled and mostly poor on the other hand has been on the rise. It can have dire implications for the social milieu but also for the sustainability of growth (Breman (2010) and Chandrasekhar \& Gosh (2007), Ranis et.al. (2000)). Without a more uniform increase in labor productivity and therefore incomes, economic expansion is eventually brought to a halt by either a lack of growth in demand or by skilled labor supply constraints; or, by a combination of the two. While overall inequality has been well documented, Deaton \& Dreze (2002) find that regional and state inequality is increasingly apparent and is driven by changes in the sectoral configuration of local economies. Southern and Western states tend to be more successful in reducing poverty-which is not surprising, since many high-productivity jobs in the IT and business services are concentrated in these states. It remains to be seen if these hubs of fast growth remain enclaves or if stronger linkages can be built with the rest of the economy such that growth accelerations become more uniform. As of now however the impact of trade in services on the Indian economy, with respect to output growthand more importantly, employment, remains relatively weak.Mitra (2011) in fact points out that because of its negligible effect on job creation the export-oriented service sector is far from being inclusive.

Second, there are significant gaps between labor productivity in the organized versus unorganized sectors. A formal sector worker produces on average eight times the output of an informal worker (Rada (2010)). The gap is even more astonishingif we compare labor productivity in the organized with unorganized manufacturing. Based on Trivedi et al (2012) the difference was on the order of fourteen folds in 2004-05. These numbers underline the profound

\footnotetext{
${ }^{1}$ The reason for high productivity growth can be explained by Kaldor-Verdoorn effects as explained later on, but potentially also by a palpable shift towards capital-intensive techniques which boosted growth and productivity at the expense of potential employment (Alessandrini, 2009).
} 
heterogeneity of the Indian economy and which mayfurther reflect in a lack of demand linkages between unorganized and organized sectors.

We can dissect the macroeconomy further to capture the effects of a lagging agricultural productivity on industrial growth potential. This aspect has long been at the heart of the development debate which points out that the price of food in terms of the industrial wage acts as a crucial constraint to industrial expansion (Kalecki (1976)). Consequently, there is the possibility that food price inflation disruptsa virtuous cycle of formal/organized sector output and employment growth. Hence, appropriate policies should be designed to aid agriculture in supporting formal and industrial growth in general.

\section{Structural change in a three-sector model}

To explore structural change in the Indian economy and the likely impact of different policies on growth sustainability we use an open economy model fed by the Social Accounting Matrix (SAM) presented in Table 1. The equations of the model, values for key parameters and a more technical presentation can be found in the appendix.

We distinguish between agricultural and non-agricultural activities and divide the latter further into two separate sectors, organized and unorganized. Hence, the economy consists of three productive sectors, the organized or formal sector $(O)$, the unorganized or informal sector $(U)$ and agriculture $(A)$ each producing one commodity; and four households defined in terms of their primary source of income i.e. formal/organized households, informal/unorganized non-agricultural households, agricultural households and capitalist households. In what follows we will use the subscriptso, $u$, a for all variables pertaining to the organized, unorganized and agricultural sector respectively.

Organized and unorganized sectors produce distinguishable and non-substitutable tradable goods using capital and labor. Agriculture utilizes labor only to produce a nontradable, agricultural good. Commodities produced by the organized and unorganized activities can be consumed, invested or exported. The foreign sector supplies intermediate inputs used in the production of all three goods. Capitalists and workers are two distinct classes within the organized sector only; capitalists own capital, save and invest; workers which make up the rest of the three households-organized, unorganized, and agricultural-receive a wage and a profit in the case of informal households which they spend entirely on consumption of all three sectors' products. Having been informed by the data for 2003-04 the model departs from the classical assumption that workers do not save, and instead adopts a constant saving rate that corresponds with the Keynesian theory of consumption.

Consumption demand by working households is determined by a standard Linear Expenditure System (LES) (Taylor (1979)). All households, aside capitalists, consume a minimum amount of food produced by the agricultural sector. Under the assumption that agricultural output is fixed, prices have to adjust to bring excess demand to zero as explained below. In this setup overall growth is constrained if households have a high consumption floor which acts as a limit on their ability to substitute away from food (von Arnim \& Rada (2011)). Finally, there is a government which collects direct and indirect taxes, purchases goods and services from organized and unorganized activities only and makes transfers to households and productive sectors in form of subsidies and other transfers. 
Macro equilibrium in our model is equivalent with simultaneous zero excess demands in all three sectors. In line with standard fixed-flex price models (Hicks (1965), Taylor (1983)) excess capacity in the organized sector implies that equilibrium in the sector is attained through quantity adjustments. The same type of adjustment is applied to the unorganized non-agricultural activities. $^{2}$ Our modeling choices in this paper are made in an attempt to conform as best as possible with the current structure of the Indian economy. First, the unorganized sector in India is vast and contributing roughly half to the economy-wide GDP. Hence, we expect that given our broad aggregation there is a large degree of heterogeneity within the unorganized sector itself. In this sense activities that are supply constrained are expected toco-exist with those activities that are demand-constrained. In general, and second, the unorganized sector tends to be labor intensive. In the context of a large reserve army of labor in the agriculture and in activities at the bottom of the unorganized sector, we ignore those few supply constraints on production that may exist and, instead, assume that the magnitude of quantity adjustment happening in the unorganized sector is superior to the price adjustment. Finally, agriculture is expected toencounter constraints on the supply side and therefore equilibrium in this sector is re-established through changes in its price level.

There are several ideas behind the workings of the economy in this model. First, the Kaldor-Verdoorn (KV) relation postulates that overall productivity growth responds to higher output growth in the industrial or formal sector and therefore is endogenous. ${ }^{3}$ Since capital accumulation is a feature of organized and unorganized activities, we assume the existence of economies of scale and therefore allow productivity to grow along Kaldor-Verdoorn lines in both sectors. However, differences in technological adoption and learning by doing exist between the two sectors. The organized sector is better equipped to take advantage of economies of scale and new knowledge and therefore its labor productivity expands at a faster rate compared to the labor productivity in the unorganized sector.

Second, labor productivity in the agriculture responds to the amount of employment (Sen (1966)). For example, a transfer of labor to the formal or unorganized sectors eventually leads to a rise in the average product in agriculture as a smaller number of workers can produce the same amount of output as before. Given that labor productivity changes with the number of workers, overall output remains fixed.

Third, employment growth in the organized and unorganized activities follows from the output-productivity dynamics. Organized jobs are lost if productivity grows faster than output or if output declines due to an exogenous shock such as a collapse in the external demand. The outcome is an increase in the structural heterogeneity of the economy with potential negative consequences on long-run development. The released labor ends up in the subsistence agricultural sector which has adverse effects on both overall productivity growth and output-the latter due to a loss in purchasing power and therefore a further decline in demand. The vicious circle replicates itself as lower output further spreads into falling rates of productivity growth

2 This is a departure from previous structuralist models such as those discussed in Taylor (1983), Rada (2007) or Rada \& von Arnim (forthcoming), and which assume that informal or subsistence sectors are supply constrained.

${ }^{3}$ Due to "...dynamic economies of scale of a microeconomic character, associated with learning and induced innovations; those associated with the exploitation of intra- and inter-sectoral external economies [...]; and the positive links generated by variations in underemployment." Ocampo (2005) 
unless macroeconomic policies to stimulate aggregate demand are implemented. ${ }^{4}$

Lastly, we assume that each sector aside of agriculture engages in capital accumulation, however, investment demand in each sector is associated only with its own produced capital goods. In line with the Keynesian-Kaleckian approach to macroeconomic modeling investment is an independent variable in the sense that it does not respond to changes in saving rates. In this sense, Say's law does not apply. In the next section we see the model at work in terms of the results it produces in the aftermath of an exogenous shock.

\section{Simulations results and sensitivity analysis}

The purpose of our three-sector model is to explore how the current structure of India's economy affects its potential for growth and structural change. We discuss four scenarios. The first two are positive demand shocks coming from investment in both sectors. Next, we consider two price shocks: a rise in the nominal wage of organized labor representing a domestic shock; and a nominal depreciation of the currency which amounts to an external shock. The simulation exercises are completed with sensitivity analyses of themodel's results with respect to price elasticities of trade and the Kaldor-Verdoorn effects on productivity in the organized and unorganized sectors.

Simulation results are presented in Table 2 below. The numbers in column (1) of each scenario are obtained under the assumption of zero elasticities across the board; column (2) results introduce Kaldor-Verdoorn effects; and column (3) turns on trade responses to changes in prices in addition to the productivity rules in the two sectors explored in the previous calibration. This last exercise represents the baseline calibration of the model where price elasticities of trade (import and export respectively) for organized sector output are set to $\left|-\phi_{o}\right|=\chi_{o}=0.75$. The same price elasticities for the unorganized sector import and export demand, and for imports by the agricultural sector, are $\left|-\phi_{u}\right|=\chi_{u}=0.3$ and $\left|-\phi_{a}\right|=0.3$ respectively.

Productivity responds more strongly to economic expansion in the organized sector. Using empirical evidence from a prolific literature on the Kaldor-Verdoorn effects, the parameter is set to $\delta_{o}=0.5$. In the unorganized sector the same parameter is lower, $\delta_{u}=0.2$. Other relevant parameters are found in the appendix. The analysis at the end of the paper sheds further light on the sensitivity of the model's results to changes in these elasticities.

\section{Demand shock}

Demand shocks in Table 2 capture effects of a 7 per cent increase in investment demand in the organized and unorganized sector respectively. Relative to the size of GDP each of these shocks amount to about 10 per cent of output. The two experiments are taken separately.

A first observation is that across the three columns for each demand-shock scenario, the growth in real GDP is relatively modest and in the order of 1 to 1.5 per cent. In fact a demand shock in the unorganized sector has a slightly stronger effect on economy-wideoutput although lower on the share oforganized employment. These results have several causes. First, they

\footnotetext{
${ }^{4}$ A more advanced setup of the labor market can be assumed if for example the reserve army from the agricultural sector gets exhausted and which is equivalent with either the disappearance of the agriculture sector or its transformation into a high-productivity, organized sector. If this was the case, the transfer of labor would take place entirely from the unorganized to the organized activities.
} 
reflects weaker backward or demand linkages from organized activities to the rest of the economy which is worrisome especially in the context of a very sizable unorganized sector. In addition, recall that each sector purchases its own-produced capital good. Hence, there is also a lack of direct demand stemming from investment between the two sectors. The concern is especially about demand for capital goods produced by organized activities. If a case is to be made for specialization, preference should be given to the organized sector as the location of investment goods production. The organized sector has an advantage in terms of knowledge and skilled labor which translates in higher labor productivity. Indeed, this is a modeling choice we made to underline the implications of a substantial degree of structural heterogeneity. One policy conclusion is that India's growth and transformation efforts can benefit from more demand linkages for intermediate and capital goods being established between the two sectors, and especially from the unorganized to the organized sector.

A second general observation is that investment demand growth in either sectors has negligible effects on structural change in terms of employment. The numbers quantifying the changes relative to the base year in the organized sector share in employment are on the orderof 0.2 percentage points. A low initial share is partially responsible for this disheartening result. ${ }^{5}$ To produce more palpable changes in the structure of employment India needs more aggressive macroeconomic policies both in terms of demand injections aswell as a result of strengthened linkages among sectors.

We explore now several other results from the three calibrations. These are related to changes in prices, changes in labor productivity and movements in sectoral net borrowing relative to GDP. Demand shocks are accompanied by a more rapid increase in the GDP deflator as can be observed from the numbers along the second row. ${ }^{6}$ Demand originating from the unorganized sector leads to a more rapid increase in prices. This result follows from our assumption that informal or unorganized households have a higher consumption floor of agricultural or food products. Overall, inflation is the result of higher prices for the agricultural product in response to higher intermediate demand from the productive sectors and higher final demand from households. The latter is due to the following chain of events: a) a demand shock ineither sector leads to a transfer of labor from low to higher pay jobs; b) a higher household income implies a higher demand for all three commodities; c) a fixed output in agriculture finally means that equilibrium can be re-established only through a rise in prices for agricultural products. Next, domestic price inflation translates into a real appreciation of the exchange rate-which is equivalent to a decline in the real exchange rate given the definition $\rho=e P^{*} / P^{7}$.

One thing to notice is that inflation and consequently the appreciation of the real exchange rate is considerably lower in columns (2) and (3) compared to the first calibration. The difference is due to Kaldor-Verdoorn effects which now kick in. Higher labor productivity reduces

\footnotetext{
${ }^{5}$ Take for instance column (1) belonging to the first scenario where all elasticities are turned off. Results (not reported in the table) show an increase in organized sector output of 1.7 per cent. In the context of no Kaldor-Verdoorn effects employment grew at the rate of output, or in other words, at a rate of 1.7 per cent as can be observed in Figure 1.

However, with a 15 per cent initial share of organized labor, the final effect from the demand shock translated in a mere 0.3 percentage points increase.

${ }^{6}$ As a reminder, the inflation numbers reported in Table 2 are calculated based on an economy-wide price index that has been constructed as a Fisher-index of prices in the three sectors. The Fisher index is the square root of the product of Laspeyres and Paasche indexes.

7 However, changes in prices affect import and export demand only under the third calibration.
} 
unit labor costs and therefore production prices for organized and unorganized goods. Exports are stimulated by this boost in competitiveness, an effect owed to a negative price elasticity of exports inthe third calibration exercise. Higher export demand in response to more competitive prices feeds back into the productivity rule through an 'economies of scale' effect. A stronger Kaldor-Verdoorn elasticity in the organized sector also means a larger productivity increase when the demand shock originates in the organized sector itself-1 per cent compared to 0.7 per cent in the case of a rise in investment demand in the unorganized sector. On the other hand, Kaldor-Verdoorn effects while helping on the external demand front limit the need for labor transfer to these sectors and therefore may suppress structural change.

Moving on to saving-investment balances for institutional sectors, the private sector experiences a deterioration of its balance $(S-I)$ relative to GDP, between 0.6 to 0.7 percentage points. A rise in private investment leads to an economicexpansion which benefits government revenues. As a result the public balance $(T-G)$ rises by about 0.4 percentage points. Finally, the economy is running a larger deficit (or a smaller surplus, depending on the starting point) with the rest of the world. This is true even if trade is inelastic with respect to prices since imports are proportionalto output and thus expand when output expands.

The above results are not very encouraging, or at least not with respect to the prospects for a swift change in the structure of the Indian economy in general, and more importantly in the sectoral employment along the lines of Chenery (1960), Chenery et.al. (1987) and Kaldor (1966). Overall, policy efforts are constrained by the limited size of the organized sector employment. A big-push policy approach may therefore be temporarily necessary although one has to ask to what extent is India capable of financing capital accumulation. FDI has been a major source for the last decade and a half although it has been slowing down recently and, truth be told, most of the growth in FDI hasbeen increasingly directed towards services instead of manufacturing. Export-led growth on the other hand is certainly not a much heralded strength of the Indian economy. Nonetheless, financial constraints, if any, may be less important than a more coordinated strategy of investment at the sectoral and macroeconomic level. In fact India's outward FDI has been increasing at a rapid pace which points out that financial capital is available (Athukorala (2009)). The question is if first, outward FDI crowds out domestic investment; and second how foreign investment can be relinked to the domestic activity.

\section{Price shocks: nominal wage and exchange rate}

Price shocks tend to have contractionary effects on the Indian economy. Organized employment in particular takes a hard hit as can be noticedin Figure 1.

A negative response from output after an upward shock in the nominal wage in the organized sector suggests significant structural bottlenecks and a redistribution of income across sectors that eventually hurt the economy. To begin with, nominal wage increases produce strong inflation for all calibrations. Consequently the real average wage for the economy declines despite a 10 percent increase in wages of organized sector workers. The reason has to do with the presence of a very large share of workers in the unorganized sector. The purchasing power of these workers is hurt by the rise in prices. The overall decline in consumption demand eventually translates into lower output. A second outcome of inflation is a strong real exchange rate appreciation. As a result, the decline in economic activity is more pronounced when trade responds to prices. 
A perverse effect is observed in terms of sectoral balances which improve visibly, especially for the first two calibrations-between 0.5 and 1 percentage point of overall output. A rise in the ratio of net exports to GDP is expected since imports contract in the aftermath of a decline in output, while at the same time exports experience no changes—recall that results in columns (1) and (2) are obtained on the basis of inelastic import and export demand with respect to prices. The private balanceimproves by half a percentage point relative to GDP as a result of a redistribution of income towards organized sector incomes. A forced saving mechanism seems to be at work. A rise in the nominal wage in the organized sector leads to an increase in the value added price for the sector $Z_{o}$, and therefore to an increase in the amount of nominal saving by wage-earners and capitalists in the sector at the expense of saving in the rest of the economy. A higher saving rate in the organized sector together with a pre-determined investment demand and a decrease in GDP give rise to a positive change in the saving-investment balance. A similar reasoning applies in the case of public net lending — tax revenues increase simply because there is a redistribution towards economic classes that are taxed at a higher rate. Nonetheless, these results are obtained in the condition of an economic decline.

Together with the overall economy labor productivity suffers across all sectors. The decline in demand in the organized and unorganized sectors translates into a loss of efficiency through the Kaldor-Verdoorn effect. For agriculture, a loss of productivity comes as a result of labor being transferred to the sector. These negative results on the economy are especially pronounced when trade is sensitive to price changes.

What are the policy lessons we can draw from these results? First, a positive nominal shock in the organized sector can have adverse effects on the economy in the presence of significant structural constraints, and a large share of the labor force in the unorganized sector. In other words, policy should be alert to existing structural bottlenecks and, it should target the purchasing power of those who make up the largest share of consumers. In India these are the unorganized workers. To have an impact on the economy through demand channels, policy would do better if it aimed to create a strong middle class. Second, to avoid inflation and the negative results described above a nominal wage increase should be accompanied by measures that increase productivity. In this way, a rise in the purchasing power of labor is obtained without a rise in unit costs and therefore prices.

With trade elasticities turned off a nominal exchange rate depreciation produces similar results for the real economy - contraction, declining presence of organized activities and a drop in labor productivity in each sector. Nominal or price effects are different. The economy is undergoing deflation when all key elasticities are zero or very low inflation when Kaldor-Verdoorn effects are on; the real exchange rate depreciates; and all sectoral balances switch sign. Deflation happens because of contraction despite the fact that costs with imports have gone up. However, there is no wage inflation in this case to counteract the negative nominal effect of the decline in output. With a decline in real income and no redistribution as in the previous case, private and public balances deteriorate. The same is true for the external balance which now worsens by about 1.5 percentage points of GDP.

The only case, and arguably the relevant one, when a price shock has a positive effect on the economy is under the conditions of price-sensitive import and export demand. The results appear in the last column of Table 2 . The economy does expand although only slightly-by 0.1 percent, organized sector increases its share of output and employment, and its labor becomes 
more productive by 0.4 per cent. The unorganized sector on the other hand suffers as a result of higher costs with imports. Contraction in the unorganized sector means a loss of employment which ends up in the agriculture. Hence, we observe a negative effect on productivity in both unorganized and agricultural sector.

\section{Sensitivity analysis}

In this section we briefly discuss the relevance of several key parametersKaldor-Verdoorn elasticities and price elasticities of import and export demand in the organized and unorganized sectors. Figures 2 through 5 capture the effect of changing elasticities on the real economy. The focuson growth rates ofoverall GDP and employment in the organized sector. Shocks for all figures correspond to the simulation exercises in Table 2. We discussthe two demand shocks but only one price shock-a nominal exchange rate depreciation.

All figures show how the relevant variable (output or organized employment) is changing in response to a varying parameter, given the shock. In all figures the values taken by the key parameter appear on the horizontal axis, while the response of the variable is plotted on the vertical axis.

Figures 2 and 3 correspond to thesensitivity analyses on trade elasticities in the organized and unorganized and agricultural sectors respectively. As expected there is a threshold above which a nominal depreciation becomes expansionary. This can be seen in the top two diagrams of each figure. Given an exchange rate shock the simulation results are more sensitive to changes in trade elasticities in the organized sector, but overall, the magnitude of the expansion is largerin the presence of varying trade elasticities for the unorganized sector. The economy responds visiblyto changes in price elasticities of import and export demand of organized sector when a demand shock is applied in either sectors-the two lower panels (b.1,b.2, c.1, c.2) in Figure 2. The bottom line is that the larger are price elasticities the more pronounced is the expansion. $A$ positive demand shock induces a rise in labor productivity through the Kaldor-Verdoorn rule which is set to 0.5 for the organized sector and 0.2 for the unorganized sector. Consequently, there is a gain in competitiveness which becomes ever more beneficial the higher is price elasticity of export demand. In contrast to these results, different levels of elasticity in the unorganized sectors produce no distinguishable reaction from the economy. The reason is that trade of unorganized sector in the base year is only a fraction of the organized sector's trade with the rest of the world. Hence, its weight vis a vis trade and GDP is too small to make a visible difference when its import and export demand elasticities are changing.

The effects of a varying Kaldor-Verdoorn coefficient in the organized sector are shown in Figure 4. The relevant graphs for the unorganized sector are in Figure 5. Both sets of results are obtained under the baseline configuration (3) for trade elasticities. What transpires rather clearly is that the more sensitive labor productivity is to demand the more pronounced is the slowdown in organized employment growth. This presents yet another challenge for policy makers. On one hand a sustainable increase in incomes and especially wages is not feasible in the long run without a rise in labor productivity as suggested by the impact of a nominal wage shock in the previous section. On the other hand, labor productivity increases reduce the need for employment growth and therefore stifles structural change. 


\section{India in the world economy}

What does India's rise mean for the world economy? What role can India play in support of global growth? These and related questions are addressed in this and a subsequent section with a model for the world economy. The motivation is simple, and can be looked at from (at least) two different angles. First, the global financial crisis, emanating from the US, had large output effects both in the US and Europe. The question arose whether fast growing large emerging economieswould be able to decouplefrom these adverse shocks. Second, both US and European economies remain weighed down by the toxic combination of balance-sheet recessions and fiscal contraction. The question arises whether fast growing large emerging economies will be able to sustain global growth; i.e. become an engine of demand. These fast growing large emerging economies are of course the BRICs: Brazil, Russia, India, China.

The following section presents a real-side one sector multi-country model of the world economy with demand-determined output, bargained distribution and endogenous productivity. The model is used further below for simulation analysis of BRICS country performance. The exposition proceeds along the following steps: First, we present a one country version in two dimensions-with all the necessary (and defensible) simplifications. The purpose is to expound the core theoretical structure of the model. We briefly discuss the multi-country model as well as the underlying data. In the following section, we motivate and analyze relevant simulations.

\section{A global model}

The model covers product and labor markets in simple but comprehensive fashion. Let us consider price and quantity setting in both markets. ${ }^{8}$ Product markets feature a "macroeconomic firm" that uses domestic factors and imported intermediates from all other regions to produce domestic value added. The firm marks up on domestic labor costs; the supply price is then a weighted average of domestic factor and import cost. Foreign cost pass-through is limited by the cost structure. The size of the mark-up depends on the degree of competition in product markets. If the firm faces little competition and as a result has high pricing power, its mark-up rate is high. High mark-ups, of course, imply high profit shares.

The level of aggregate demand for the firm's product is a function of expenditure levels, the multiplier and the real exchange rate. Expenditure levels-real private investment and real public expenditures-are exogenous in this model. The multiplier, however, increases with redistribution towards wage earners, due to their lower propensity to save. In that fashion, expenditures, prices and distribution all affect the level of demand, and household's income.

There are two households, workers and capital owners. The two bargain in labor markets over nominal wages, the single argument being the rate of unemployment. The lower the rate of unemployment, the higher nominal wages, and vice versa. Further, labor productivity depends on demand conditions, due to labor hoarding as well as overhead labor. Labor hoarding refers to the fact that the firm retains skilled employees throughout a downturn because retraining new employees in the upturn would be costlier; overhead labor refers to the fact that firms usually have some back-office and managerial staff not easily made expendable. The ratio of the real wage and labor productivity is equal to real unit labor cost, or, in other words, the wage share.

\footnotetext{
${ }^{8}$ The discussion of the model here largely follows von Arnim (2010) and von Arnim (2011). Financial support from the International Institute for Labour Studies (IILS, ILO) for those studies is gratefully acknowledged.
} 
We can think through an example to tie it all together. Suppose that business confidence improves and investment increases. Unemployment decreases with the expansion of demand. As just laid out, nominal wages rise. Output prices rise, but moderately, so that real wages increase. On the other hand, productivity increases as well with the expansion of demand. Whichever increases faster determines whether the distribution of income tilts in favor of owners or workers. Internationally, the increase in demand leads to higher imports. The rise in prices domestically leads to some real appreciation, which further increases imports-and decreases exports. The fall in the current account is equivalent to a rise in capital inflows, which in part finance the original outlays for business investment. Below we present a stylized one country model in order to set the stage for what follows in multi-country contexts further below. The model is presented in two dimensions: the rate of utilization and the labor share. ${ }^{9}$

Let us begin with the components of effective demand:

$$
\begin{aligned}
& c=\frac{c}{K}=(1-s[\psi]) u \\
& g=I / K=\bar{g}(2) \\
& v=(E-M) / K=v[u, \psi],(3)
\end{aligned}
$$

where $c, \bar{g}, v$ are consumption $C$, (gross) investment $I$ and net exports $E-M$ relative to capital stock $K . c$, vare functions of the rate of utilization $u=Y / K$ and the labor share $\psi \cdot{ }^{10}$ The signs of the partial derivates of these demand functions are standard: $s_{\psi}<0$, since redistribution towards wage earners reduces the average savings propensity; $v_{u}>0$ through the import channel, and $v_{\psi}<0$ through the export channel, since higher real unit labor costs represent a loss of price competitiveness.

Real unit labor costis defined as $\psi=\frac{w L}{P Y}=\frac{\omega}{\xi}$, where

$$
\begin{aligned}
& \omega=w / P=\omega[u, \psi](4) \\
& \xi=Y / L=\xi[u, \psi],
\end{aligned}
$$

meaning both the real wage $\omega$ and labor productivity $\xi$ are functions of the rate of utilization and costs. The real wage responds positively to demand $\left(\omega_{u}>0\right)$ due to the link from goods to labor markets. Higher demand leads to higher activity, which necessitates hiring —which in turn improves employee's bargaining position. Thus, the relevant variable is the employment rate, but for the sake of simplicity, the chain of causation is summarized here by $u$. Workers, obviously, can bargain only for nominal wages, so to simplify in this manner it is further necessary to assume that firms can recoup at most a fraction of nominal wage increases by price rises, and that these are anticipated.Further, the real wage responds positively to labor productivity, $\omega_{\xi}>0$. Simply put, workers demand to share productivity gains; such bargaining behavior is observed and is consistent with the desire (and tendency) to maintain stable income shares. It implies that the real wage responds negatively to the labor share, $\omega_{\psi}<0$. In other words, elevated real unit

9 The relevant literature is long; it shall suffice here to mention Rowthorn (1982), Dutt (1984), Taylor (1985), Bhaduri \& Marglin (1990) and Barbosa \& Taylor (2007) as selected seminal papers.

10 The rate of utilization is proxied by the income-capital ratio. The actual rate of utilization is the ratio of current to full employment output; multiplying it by the (constant and normalized to unity) full employment-capital ratio we get $u$ as defined. 
labor costs—high real wages relative to labor productivity-lead to decreases in real wages, and vice versa.

Labor productivity, in turn, is a positive function of demand along well known lines. Okun's Law provides empirical evidence for a short-run positive relationship between economic activity and labor productivity. It is primarily due to labor hoarding: Firms retain skilled and overhead labor in a downturn, and as they are "getting busy again" in the upturn, average employee productivity rises. Kaldor-Verdoorn effects are relevant over longer time horizons, and due to specialization, learning by doing etc. In summary, $\xi_{u}>0$. Further, labor productivity responds positively to costs, $\xi_{\psi}>0$ : High real unit labor costs provide incentives for firms to "squeeze labor for effort," rather than hire.

To assess characteristics and stability of the model, let us specify functions for the time rate of change $d u / d t=\dot{u}$ and $d \psi / d t=\dot{\psi}$ :

$$
\begin{aligned}
& \dot{u}=\alpha\left(u^{d}-u\right)=\alpha((1-s[\psi]) u+\bar{g}+v[u, \psi]-u)(6) \\
& \dot{\psi}=\beta\left(\psi^{d}-\psi\right)=\beta\left(\frac{\omega[u, \psi]}{\xi[u, \psi]}-\psi\right),
\end{aligned}
$$

where $u^{d}$ and $\psi^{d}$ are the rate of utilization and the labor share implied by effective demand and distribution (real wage bargaining and productivity). The change in $u$ and $\psi$ follows as the difference between these and current levels of output and the prevailing distribution, respectively. The speed of adjustment depends on the magnitude of sign-preserving coefficents $\alpha, \beta>0 . \dot{u}$ is a standard excess demand function, and $\dot{\psi}$ is a partial adjustment equation for the labor share. The Jacobian matrix (with $\alpha=\beta=1$ without loss of generality) of this two-dimensional system of differential equations is

$$
J=\left(\begin{array}{lll}
v_{u}-s & v_{\psi}-s_{\psi} u \\
\omega_{u} \frac{\psi}{\omega}-\xi_{u} \frac{\psi}{\xi} & \omega_{\psi} \frac{\psi}{\omega}-\xi_{\psi} \frac{\psi}{\xi}-1
\end{array}\right)=\left(\begin{array}{ll}
\frac{\partial \dot{u}}{\partial u}<0 & \frac{\partial \dot{u}}{\partial \psi} \gtrless 0 \text { PL/WL } \\
\frac{\partial \dot{\psi}}{\partial u} \gtrless 0 \text { FS } / \mathrm{PS} & \frac{\partial \dot{\psi}}{\partial \psi}<0
\end{array}\right)
$$

The top left entry is the dynamic multiplier. For stability in the goods market, it must be negative; meaning the sum of the propensities to save $(s)$ and import $\left(v_{u}<0\right)$ must be negative. The bottom right entry describes distributive own-feedback. For stability, its sign must be negative. Since $\omega_{\psi}<0$ and $\xi_{\psi}>0$, it must be negative. The off-diagonal entries describe cross feedbacks. On the top right, (net) export response to labor share increases is negative, but $-s_{\psi} u>0$, so that the aggregate sign depends on relative magnitudes. As is standard in the Neo-Kaleckian literature, an overall negative (positive) sign denotes profit-led (wage-led) demand. Second, on the bottom left, both real wages and productivity respond positively to higher demand. The sign of the entry will depend on the relative magnitudes of the two effects. A positive sign suggests successful employee bargaining, a negative sign suggests successful firm bargaining, relative to demand-induced productivity gains. The former is often labelled as a profit squeeze, the latter as forced saving-summarized in the inequalities of the Jacobian above.

For stability, the determinant of the Jacobian must be positive, $|J|>0$, and the trace of the Jacobian must be negative, $\operatorname{Tr}[J]<0$. The latter will always be satisfied, since both entries along the main diagonal are less than zero. The determinant will be positive if the off-diagional entries are of opposite sign or small relative to the main diagonal. 
From this one-sector one-country model, it is fairly straightforward to transition to the multi-country model. The equations of the multi-country model are presented in Table 3. Importantly, all equations are specified in levels, rather than rates of change. ${ }^{11}$ The dynamic specification above provided simple conclusions on behavior and stability for the one-country model. However, the dynamics evolve around an equilibrium, so that the comparative static exercises of the static multi-country model are qualitatively the same. For stability, it is sufficient to have positive multipliers in all countries, and not to have "large" distributive feedbacks. Of course, the larger model permits endogenous determination of prices: bargaining concerns nominal wages; and, given the mark-up, firms pass on changes in nominal unit labor costs. ${ }^{12}$

The global data set covers a large share of the world's national economies-one hundred and sixty countries. Their relative size and their geographical trade relationships play a crucial role. The model dataset is aggregated into sixteen countries and regions; the countries are US, Japan, Canada, and the BRICS (Brazil, Russia, India, China and South Africa), ${ }^{13}$ the regions Africa, Asia, Eurozone, the rest of Europe, and Latin America and the Carribean. Countries with more than half of their exports concentrated in petroleum and related products as well as natural gas are grouped together. Asia and the Eurozone are further disaggregated into surplus and deficit regions. The principal source for the bilateral trade matrix is the IMF's Direction of Trade Statistics. The trade data is presented by "reporting countries" and "partner countries" for exports and imports. Labor market data is summarized by the unemployment rate. It is based on population, labor force, employment and unemployment data from national statistics offices, regional development banks as well as ILO's Laborsta and EAPEP databases. Reported unemployment rates are used where available, estimates based on the highest quality underlying data where not. For most data, the base year is 2008. For a thorough discussion of the data set, see the appendix in von Arnim (2010).

\section{Simulations and discussion}

Let us restate the central question to be addressed here: What does India's rise mean for the world economy? What role can India_and other BRIC countries_play in support of global growth? To anticipate our conclusions: Probably a limited role. While growth in many emerging markets has remained strong or recovered quickly, it appears that this might be due in large part due to successful stimulus efforts. Global demand links from and to BRIC countries are still weak relative to global demand links from and to US and Europe.

We can have a first look at this through the lens of linkage analysis. The method was

\footnotetext{
${ }^{11}$ The model falls within the general category of empirical economy-wide models, often labeled Computable General Equilibrium (CGE) models. A CGE model is based on a Social Accounting Matrix (SAM), which depicts detailed data on relations of production and distribution between main socio-economic agents in an economy. The model adds behavioral relationships to the accounting; econometric evidence is applied to calibrate relevant parameters. The complete model can then be used to calculate counterfactuals in response to assumed shocks and policies. For standard discussions of the methodology, see Robinson (2003) and Taylor (2004).

${ }^{12}$ The nominal wage increases with higher labor productivity. In the model above, that was expressed through a negative response of the real wage to the wage share. Here, the nominal wage is a positive function of employment rate and labor productivity. Labor productivity, in turn, depends in standard fashion on demand conditions, due to labor hoarding as well as overhead labor-but further increases in the real wage. Since value added (and output) prices follow "passively," this setup produces a positive feedback between real wages and labor productivity.

${ }^{13}$ The original BRICs do not include South Africa. Since South Africa is so crucial an economy on the African continent, it is included here as a single country.
} 
suggested in

Chenery \& Watanabe (1958) and, for example, further developed in Syrquin \&Chenery (1989). Usually, the goal is to identify strength of inter-sectoral demand links in an input-output table. Here, we apply the same concepts to the trade matrix to identify backward and forward demand linkages between a set of countries and regions.

\section{Linkages through trade}

Direct backward (forward) linkages are column (row) sums of the trade flow matrix divided by column (row) country. Indirect backward (forward) linkages are column (row) sums $(I-M)^{-1}$, where $I$ is the identity matrix and $M$ the trade flow matrix scaled by column (i.e. importing) country. Direct and indirect linkages are weighted by country GDP (relative to US GDP), and then normalized around zero: A positive and high value indicates existing and strong linkages. Backward linkages indicate the impact of a unit increase of demand of a country on all other countries; forward linkages indicate the impact of a unit increase of demand in all other countries on the country under consideration. Put differently, backward linkages show a demand "pull" effect-the degree to which a country's growth requires other countries' outputs, and forward linkages a demand "push" effect-the degree to which a country's output is required as in input to other countries' growth.

Table 4 summarizes results: Europe and US have very strong backward and forward linkages. The BRICs appear in the lower part of the table; all with very weak linkages. China proves the exception: the manufacturing giant's large trade surplus implies at least weak forward linkages. (The countries and regions are ranked by the sum of the averages of direct and indirect backward and forward linkages, thus measuring the overall importance through demand "pull and push" effects.) The ranking in the table is dominated by country GDP size. The larger a country's GDP, the greater the weight on the linkages. Unweighted linkage measures, however, indicate the impact of a unit change of the country's GDP. Weighted linkage measures indicate the impact of such a change relative to world GDP, which is obviously the relevant metric. It follows that the ranking in the table is influenced as well by the aggregation scheme. Individual European countries would be ranked lower than if weighing in as a bloc.

It does, however, make sense to use this aggregation scheme. Obviously, the US features large as an individual country. Europe acts globally as a trading bloc, rather than individual countries; and it has a single currency. This does not apply to the same degree to the composite region of Asia, but the relevant comparison is between US and Europe on the one hand, and individual BRIC countries on the other. In summary, US and Europe tend to benefit strongly from global growth through forward linkages, and the world benefits from US and European growth through backward linkages. The reverse conclusion matters in current circumstances: US and Europe in recession limit global growth. Growth in the BRIC countries and especially India, on the other hand, has only a limited impact on global growth.

\section{Demand shocks: Local and global impact}

Simulation results confirm these insights. ${ }^{14}$ Tables 5 and 6 summarize simulation results for an investment expansion in BRIC countries and the developed world, respectively. In both cases,

\footnotetext{
${ }^{14}$ We will not discuss model calibration here. Von Arnim $(2010,2011)$ present details on behavioral parameters as well as sensitivity analysis.
} 
investment in each country is increased by one percent of GDP, simply to compare the global effects of growth in the BRIC countries and the developed world (US, Europe, Japan).

In the "BRIC growth" scenario, BRIC countries experience growth. Since wages and prices (and real wages) are pro-cyclical, all countries see some real appreciation. The price-adjusted multiplier, however, is still larger than one in all countries. Across the four BRIC countries, the external balance relative to GDP worsens: capital inflows must partially finance the private investment increase. The private balance (saving - investment) relative to GDP falls. The expansion increases government revenue, so that with constant real public expenditures the public balance improves. (Overall, the sum of the changes in public and private balances is equal to the change in the foreign balance.) Crucially, the model suggests that BRIC growth leads to negligible developed country growth, and that global growth is very weak.

In sharp contrast, the "developed country growth" scenario shows not only significant global growth but as well growth in the developing world-including the BRIC countries. To be sure, the result is driven by the relative size of developed economies, which implies that the one-percent-of-GDP investment expansion is larger in absolute terms. That, however, is exactly the point: A "regular" expansion in these regions has a significant impact on BRIC countries and the rest of the world, whereas the same cannot be said to apply in reverse. Furthermore, due to strong backward linkages especially from US and Europe to the rest of the world, repercussion multipliers lead to a strong full multiplier (in excess of two) in the developed world. (Repercussion multipliers include the positive demand effect from abroad after a domestic positive demand shock.) In summary, the model suggests that growth (or the lack thereof) in developed countries has relatively strong positive (adverse) affects in BRIC countries.

Tables 7-10 further corroborate these results. Each of these tables focuses on a demand injection inone BRIC country in detail. Figure 6 provides a different look at the same theme. The chart summarizes model results in response to a one-percent-of-GDP investment shock in each region or country. The statistic considered is global real GDP growth (top left cell in the tables above), indexed by Europe's result. As an example, consider Japan: A positive investment demand shock of $1 \%$ of Japan's GDP in Japan leads to global real GDP growth roughly one quarter as strong as a positive investment demand shock of $1 \%$ of Europe's GDP in Europe. The BRICs rank low, and India third from the bottom -in line with relative GDP size.

To conclude, BRIC countries might well matter at the margin for global growth. Certainly, BRIC country growth matters greatly for BRIC country residents. But overall, growth from a lower base and with still weaker trade links suggests that talk of decoupling -in the sense of being shielded from US and Europe recessions as well as acting as a global growth engine-is premature.

\section{Conclusions}

This paper addresses India's structural transformation and role in the world economy. India's accelerated growth in recent years has lead to much praise, but as well to questions about sustainability, resilience and inclusiveness of that performance. Based on simulation results from the structuralist three sector model of development employed here, sustained growth requires strengthened links between formal and informal activities. Further, based on simulation results from a global model with demand determined output and distributive bargaining, India-and other 
BRIC countries-are unlikely to take over as engines of growth in the world economy. Their relative size is still too small; indeed, the lack of global linkages suggests that the old adage of the US sneezing and the world catching a cold might still matter. 


\section{Appendix: A three-sector model}

The three-sector model adopted in this paper borrows the modeling framework and setup from von Arnim \& Rada (2011). At the origin it is the standard fixed-flex price model developed by Taylor (1983) and later explored by Rada (2007) and Rada \& von Arnim (forthcoming).

The structure of the economy is presented in the SAM in Table 1 and has been briefly discussed above. The data comes from Saluja \& Yadav (2006) and Ojha et.al. (2009). We focus on three productive sectors: (1) organized activities, (2) agriculture and (3) unorganized non-agricultural activities; and six institutional sectors-four types of households, government and the rest of the world.

The SAM meets the basic accounting constraints. The NW three by three matrix is the input-output table which captures intermediate demands. Along the top three rows we have final sales by sectors, while along the three columns we observe production costs-intermediates, factor costs, production taxes (net of subsidies), and imports. Transfers from government and from the rest of the world to households are found in the middle cells of the SAM. Lastly, the FOF row capture saving by each institutional sector.

Organized and unorganized activities are similar in the sense that each are assumed to hold excess capacity and that each can take advantage of dynamic economies of scale as captured by the Kaldor-Verdoorn effects. As discussed by von Arnim \& Rada (2011) the assumption of a fixed technology and limited fertile land implies that agricultural output is pre-determined, and does not vary with changing levels of labor supply. Agricultural labor productivity is endogenous, and responds negatively to a demand expansion in the other sectors which leads to hiring there, and therefore to a reduction of surplus labor in agriculture. However, average labor productivity increases automatically such that agricultural output, indeed, remains constant.

The above story can be specified formally as follows. Let $Y$ be the real GDP and $L$ an index of total employment. We define the level of labor productivity as $\xi_{L}=\frac{Y}{L}$ which through log-differentiation leads to its growth rate ex-post:

$$
\hat{\xi}_{L}=\hat{Y}-\hat{L},
$$

where a "hat" over a variable indicates the growth rate of said variable. Adopting the Kaldor-Verdoorn specification for labor productivity in the organized and unorganized sectors we get:

$$
\xi_{L i}=\delta_{0} Y_{i}^{\delta_{i}}
$$

where the sub-index $i$ denotes the sector, $\delta_{0}$ is the productivity trend and $\delta_{i}$ is the sectoral demand elasticity of productivity. The behavioral function (2) means in growth terms that $\hat{\xi}_{i}=\hat{\delta}_{0}+\delta_{i} \hat{Y}_{i}$ and further that employment in the sector $i$ follows from $\hat{L}_{i}=\hat{Y}_{i}-\hat{\xi}_{L i}$, or, in level terms:

$$
L_{i}=\delta_{0}^{-1} Y_{i}^{1-\delta_{i}}
$$

for $i=o, u$, where $\xi_{i}$ is sectoral labor productivity. For the agriculture the relevant closure is: 


$$
\xi_{a}=\frac{Y_{a}}{L_{a}}
$$

where $Y_{a}$ is pre-determined in real terms and $L_{a}$ is obtained as a residual after employment in the organized and unorganized sectors have been calculated according to (A3).

\section{Output and employment}

Real output in the organized and unorganized sectors $X_{i}$ is calculated from the demand side as the sum of intermediate demands, consumption $C_{i}^{j}$ where $j$ specifies the type of household, investment $I_{i}$, government expenditures $G_{i}$ and exports $E_{i}$ :

$$
X_{i}=\sum_{j}^{3} a_{i j} X_{0}+C_{i}^{j}+G_{i}+I_{i}+E_{i} \text { where } \mathrm{i}=\mathrm{o}, \mathrm{u} \text {, and } \mathrm{j}=\mathrm{o}, \mathrm{u}, \mathrm{a}
$$

Total consumption of the sector's product decomposes by sources of demand, $C_{i}=C_{i}^{o}+$ $C_{i}^{a}+C_{i}^{u}$, where subscripts denote the type of product, and (capitalized) superscripts the origin of demand for that product in this case the three consuming households-wage-earning households from the organized sector, agricultural households and unorganized households respectively. We provide further details on the specification of the consumption functions later on.

Unlike the organized and unorganized sectors, the level of agricultural output is capacity-constrained, and just proportional to inherited capital:

$$
X_{a}=\gamma K_{a}=\bar{X}_{a}
$$

Value added in the three sectors is proportional to real outputs. Having used already the degree of freedom from the cost decomposition along each sector's column for the determination of the output price, we adopt a behavioral relationship to determine the sectoral value added. We can write the share of domestic value added in supply as:

$$
\mu_{j}=\frac{Y_{j}}{X_{j}}=1-\left(\sum_{j}^{3} a_{j i}+t_{j}^{X}+f_{j} e\right) \text { where } \mathrm{i}=\mathrm{j}=\mathrm{o}, \mathrm{u}, \mathrm{a}
$$

where $t_{j}^{X}$ is a production tax net of subsidies, $f_{j}=M_{j} / X_{j}$ is the sectoral import propensity and $e$ is the nominal exchange rate, quoted as the domestic currency price of a unit of foreign currency. Further, value added is then determined from $Y_{j}=m_{j} X_{j}$. Unless either the nominal exchange rate $e$ or $f_{j}$ varies, $m_{j}$ takes the base year value.

Next, and identical to von Arnim \& Rada (2011), trade responds to price changes based on standard specifications:

$$
\begin{aligned}
& M_{j}=\phi_{j}^{0} \rho_{j}^{-\phi_{j}} X_{j} \\
& E_{j}=\chi_{j}^{0} \rho_{j}^{\chi_{j}} X_{j}^{f},
\end{aligned}
$$

where $e P_{j}^{*}$ is the foreign price of tradable goods expressed in the domestic currency, $P_{j}$ is the domestic goods price, and $\rho_{j}=\frac{e P_{j}^{*}}{P_{j}}$ is the sector's relative price or a measure of the real 
exchange rate. Price elasticities of import demand $\phi_{j}$ and export demand $\chi_{j}$ can vary substantially across sectors and are some of our key parameters in the model.

Lastly, and as already stated, investment and government expenditures on industry output are exogenous. Consumption is determined by a standard Linear Expenditure System (LES) as explained below.

\section{Prices and distribution}

The model features three sectoral output prices $\left(P_{o}, P_{u}, P_{a}\right)$, three sectoral value added prices $\left(Z_{o}, Z_{u}, Z_{a}\right)$, three nominal wage rates $\left(w_{o}, w_{u}, w_{a}\right)$, and a set of two profit rates $\left(r_{o}, r_{u}\right)$ and two corresponding sectoral profit shares $\left(\pi_{o}, \pi_{u}\right)$. Although we distinguish between profits and wages in the unorganized sector, the assumption is that both of these incomes go to the same households.

Let us begin with output prices in sector $o$ and $u$. Prices are cost-determined from the columns in the SAM as a weighted average of all cost components-domestic intermediates, the factor cost index $Z$ and imported inputs:

$$
P_{i}=\sum_{j, j \neq i}^{3} \frac{a_{j i}}{v_{i}} P_{j}+\frac{\mu_{i}}{v_{i}} Z_{i}+\frac{f_{i}}{v_{i}} e P_{i}^{*} .
$$

where $v_{i}=1-a_{i i}-t_{i}^{X}$. The corresponding value added prices for $i=o, u$ are

$$
Z_{i}=\frac{1}{1-\pi_{i}} \frac{w_{i}}{\xi_{i}}
$$

where $w_{i} / \xi_{i}$ are sectoral nominal unit labor costs and $1 /\left(1-\pi_{i}\right)=1+\tau_{i}$ are sectoral mark-up factors.

The price of agricultural output adjusts to clear excess demand. Since $X_{a}$ is exogenous, $P_{a}$ clears excess demand in the sector, and thus is proportional to:

$$
P_{a} \propto \sum_{i}^{3} a_{a i} X_{i}+C_{a}^{N}+C_{a}^{A}+C_{a}^{U}-X_{2}
$$

whereas the net price $Z_{a}$ clears the cost decomposition, and can be written as

$$
Z_{a}=\frac{\left(1-a_{a a}-t_{a}^{X}\right)}{\mu_{a}} P_{a}-\sum_{j, j \neq 2}^{3} \frac{a_{j a}}{\mu_{a}} P_{j}
$$

Nominal wage in the agriculture is as well endogenous. It varies to clear the income-value added identity, so that

$$
w_{a}=\frac{Z_{a} Y_{a}}{L_{a}}=P_{a} \xi_{a}
$$

Hence, the real wage per worker expands at the same pace as the labor productivity in the sector, which itself is determined by the flow of labor to and from the agricultural sector. In summary, $P_{a}$ responds to demand; $Z_{a}$ responds net income per unit, in other words, to the excess of $P_{a}$ over costs; and $w_{a}$ responds to $Z_{a}$ and labor productivity. 
Nominal wages in the other two sectors are exogenous, but profit rates vary with the distribution of income and economic activity as in the standard Kaleckian models. The two sectoral profit rates are allowed to differ. From the definition of the capital share, the profit rates can then be written as

$$
\begin{gathered}
r_{o}=\pi_{o} \frac{Z_{o} Y_{o}}{P_{o} K_{o}} \text { and } \\
r_{u}=\pi_{u} \frac{Z_{u} Y_{u}}{P_{u} K_{u}} .
\end{gathered}
$$

The mark-up rates $\tau_{o}$ and $\tau_{u}$ are exogenous, implying that the distribution of factor income in these two sectors is exogenous. The overall profit share $\pi$ is just total profit income as a share of aggregate GDP, $P_{y} Y$. The GDP-deflator $P_{y}$ is calculated as a Fisher-index of the three sectoral prices (see von Arnim \& Rada (2011) for details).

\section{Consumption equations}

Demand functions for consumer households are derived from a standard Linear Expenditure (LES) system. A generic system of demand for a three commodities economy is:

$$
\begin{gathered}
C_{o}^{j}=c_{o}^{j} \frac{Y_{d}^{j}-P_{a} C_{F}^{j}}{P_{o}} \\
C_{u}^{j}=c_{u}^{j} \frac{Y_{d}^{j}-P_{a} C_{F}^{j}}{P_{u}} \\
C_{a}^{j}=\left(c_{o}^{j}+c_{u}^{j}\right) C_{F}^{j}+\left(1-c_{o}^{j}-c_{u}^{j}\right) \frac{Y_{d}^{j}}{P_{a}} .
\end{gathered}
$$

where $j$ is the type of household and $C_{F}^{j}$ is its consumption floor of agricultural product which is assumed to be food or food-related, and $Y_{d}$ is the household's disposable income.

Saving takes place in all households across sectors. The data for 2003-04 shows that saving rates as a percentage of gross income, including transfers from the government and the rest of the world, varies between 5 per cent of the income of some of the rural households to over 30 per cent for the urban organized households or the self-employed.

A first assumption is that in the organized sector only the wage earners consume. Organized working households disposable income is $Y_{d}^{o}=\left(1-t_{Y}^{o}-s_{w}^{o}\right)\left(\left(1-\pi_{o}\right) Z_{o} Y_{o}+r m_{o}+\right.$

$t r_{o}$ ), where $\pi_{o}=1-\frac{w_{o} L_{o}}{Z_{o} Y_{o}}$ is the sectoral capital share, $t_{Y}^{o}$ is the tax rate on sectoral wage income, $s_{w}^{0}$ is the saving rate of working households in the organized sector, and $r m_{o}$ and $t r_{o}$ are transfers from the rest of the world and government respectively. Organized households demand all three goods, and consume a minimum "floor" amount of agricultural product, $C_{F}^{o}$. Analogously, $a$ - and $u$-households disposable income are $Y_{d}^{a}=\left(1-t_{Y}^{a}-s^{a}\right) Z_{a} Y_{a}+r m_{a}+t r_{a}$ and $Y_{d}^{u}=\left(1-t_{Y}^{u}-s^{u}\right) Z_{u} Y_{u}+r m_{u}+t r_{u}$ respectively, and their floor consumption of agricultural product are $C_{F}^{a}$ and $C_{F}^{u}$.

Organized sector profit recipients, the $C$-households, do not consume. Their income is $Y^{C}=\pi_{o} Z_{o} Y_{o}+t r_{\pi}$. Finally, profit income is taxed at the rate $t_{Y}^{c}$. 


\section{References}

Athukorala, P.-C. (2009). Outward foreign direct investment from india. Asian Development Review, 26, no. 2:125-153.

Barbosa-Filho, N. H. and Taylor, L. (2007). Distributive and Demand Cycles in the US-Economy-A Structuralist Goodwin Model. Metroeconomica, 57:389-411.

Bhaduri, A. and Marglin, S. (1990). Unemployment and the Real Wage: The Economic Basis for Contesting Political Ideologies. Cambridge Journal of Economics, 14(4):375-393.

Breman, J. (2010). Indias's social question in a state of denial. Economic and Political Weekly, 45:42-46.

Chandrasekhar, C. P. and Ghosh, J. (2007). Recent employment trends in India and China: An unfortunate convergence? Social Scientist, 35:19-46.

Chenery, H. B. (1960). Patterns of industrial growth. The American Economic Review, 50(4):624-654.

Chenery, H., Robinson, S., and Syrquin, M. (1987). Industrialization and Growth: A Comparative Study. A World Bank Publication.

Chenery, H. B. \& Watanabe, T. (1958). International Comparisons of the Structure of Production. Econometrica, 26, 487-521

Deaton, A. and Drèze, J. (2002). Poverty and inequality in india: A reexamination. Economic and Political Weekly, 7 September:3729-3748.

Dutt, A. K. (1984). Stagnation, Income Distribution and Monopoly Power. Cambridge Journal of Economics, 8(1):25-40.

Gandolfo, G. (2010). Economic Dynamics. Springer, 4th edition.

Hicks, J. (1965). Capital and Growth. Oxford University Press.

Kaldor, N. (1966). Causes of the Slow Rate of Growth of the United Kingdom. Cambridge, UK: Cambridge University Press, London.

Kalecki, M. (1976). Essays on developing economies. Humanities Press.

Mitra, A. (2011). Trade in services: Impact on employment in india. The Social Science Journal, 48(1):72-93.

Naastepad, C. W. M. (2006). Technology, Demand and Distribution: A Cumulative Growth Model with an Application to the Dutch Productivity Growth Slowdown. Cambridge Journal of Economics, 30(3):403-434.

Ocampo, J. A. (2005). Beyond Reforms. Structural Dynamics and Macroeconomics Vulnerability, chapter The Quest for Dynamic Efficieny: Structural Dynamics and Economic Growth in Developing Countries, pages 3-43. Stanford University Press.

Ojha, V., Pal, B. D., Pohit, S., and Roy, J. (2009). Social accounting matrix for india. mime.

Pyatt, G. 1988. The SAM Approach to Modeling. Journal of Policy Modeling, 10, 327-352

Rada, C. (2007). Stagnation or Transformation of a Dual Economy through Endogenous Productivity Growth. Cambridge Journal of Economics, 31:711-40.

Rada, C. (2010). Formal and informal sectors in China and India. Economic Systems Research, 22:129-53.

Rada, C. and von Arnim, R. L. (forthcoming). Structural transformation in china and india: A note on macroeconomic policies. Structural Change and Economic Dynamics.

Ranis, G., Stewart, F., and Ramirez, A. (2000). Economic growth and human development. World Development, 28(2):197-219.

Robinson, S. 2003. Macro Models and Multipliers: Leontief, Stone, Keynes, and CGE Models. International Food Policy Research Institute (IFPRI)

Rowthorn, R. E. (1982). Demand, Real Wages and Economic Growth. Studi Economici, 18:3-53.

Saluja, M. R. and Yadav, B. (2006). Social accounting matrix for india 2003-04. India Development Foundation.

Sen, A. K. (1966). Peasants and dualism with or without surplus labor. Journal of Political Economy, 74.

Syrquin, M. \&Chenery, H. B. (1989) Patterns of Development, 1950 to 1983. World Bank.

Taylor, L. (1979). Macro models for developing countries. Mc.

Taylor, L. (1983). Structuralist Macroeconomics: Applicable Models for the Third World. Basic Books.

Taylor, L. (1985). A Stagnationist Model of Economic Growth. Cambridge Journal of Economics, 9:383-403.

Taylor, L. (2004). Reconstructing Macroeconomics: Structuralist Proposals and Critiques of the Mainstream. Harvard University Press.

Trivedi, Pushpa,L. Lakshmanan, R. Jain and Y.K. Gupta (2012), Productivity, Efficiency and Competitiveness of the Indian Manufacturing Sector, Study No. 37, Development Research Group.

von Arnim, R. (2010) Employment prospects: A global model of recovery and rebalancing. International Institute for Labour Studies (IILS, ILO) Discussion Paper No.203

von Arnim, R. (2011) Core labor standards, wage-productivity linkages and growth. Mimeo, International Institute for Labour Studies (IILS, ILO)

von Arnim, R. and Rada, C. (2011). Labour productivity and energy use in a three-sector model: An application to Egypt. Development and Change, 42(6):1323-1348. 


\section{Tables and figures}

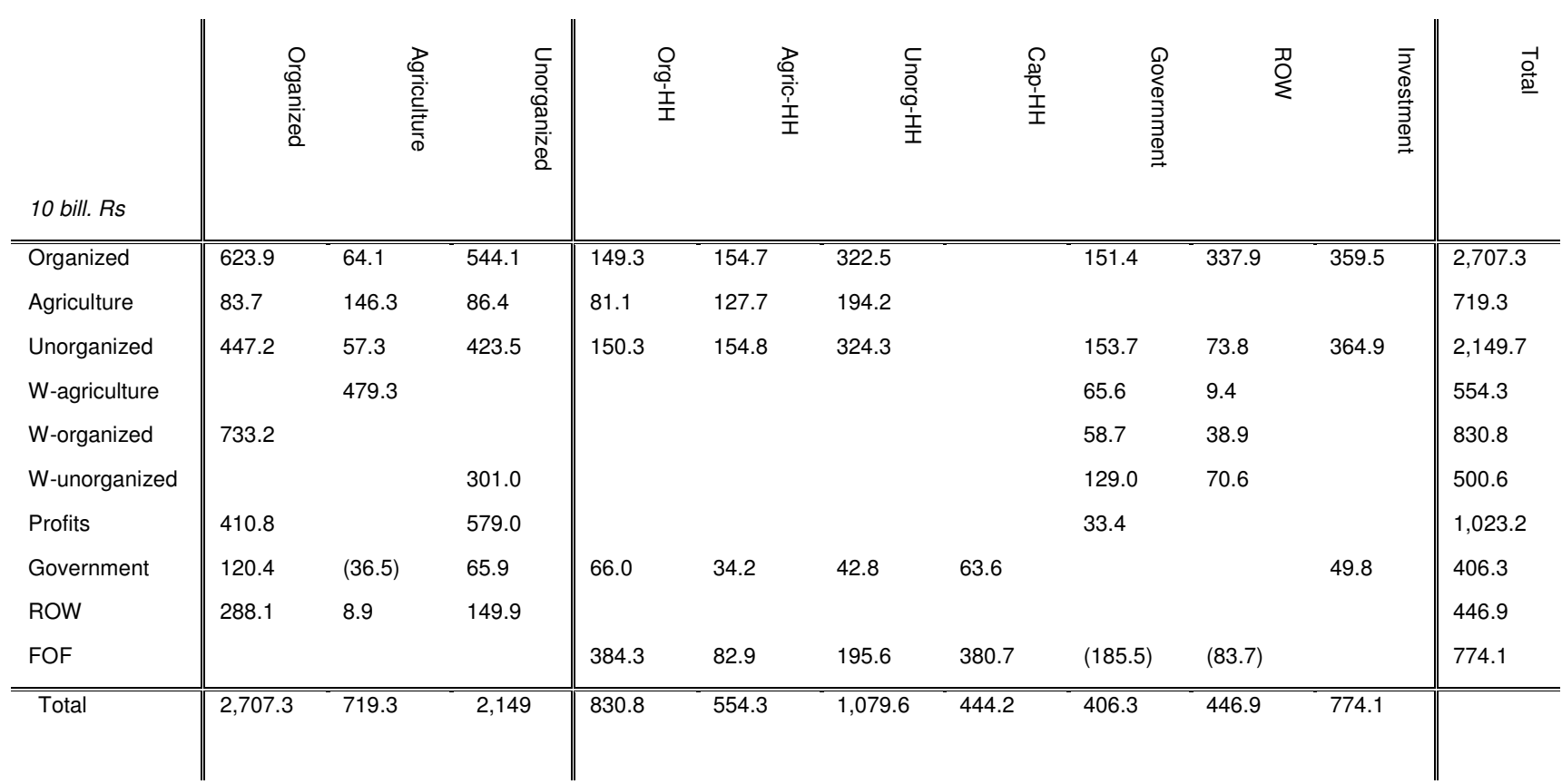

Table 1: A Social Accounting Matrix for 2003-04. Source: Aggregation based on Ojha, V., Pal, B. D., Pohit, S., and Roy, J. (2009). Social accounting matrix for India. mimeo, and Saluja, M. R. and Yadav, B. (2006). Social accounting matrix for india 2003-04. India Development Foundation.

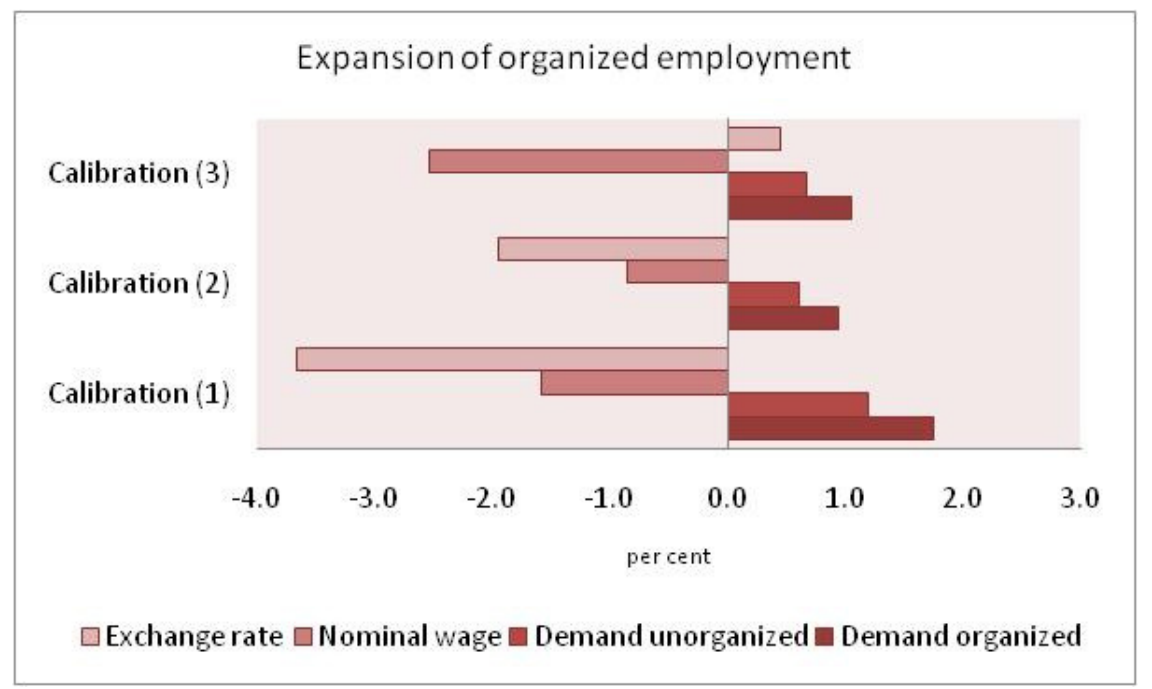

Figure 1: Simulation results. The rate of expansion in organized employment under different shock scenarios and calibrations. 


\begin{tabular}{|c|c|c|c|c|c|c|c|c|c|c|c|c|}
\hline \multirow[b]{3}{*}{ Macroeconomic statistics } & \multicolumn{3}{|c|}{$\begin{array}{l}\text { Demand } \\
7 \% \text { real investment } \\
\text { increase in the } \\
\text { organized sector }\end{array}$} & \multicolumn{3}{|c|}{$\begin{array}{l}7 \% \text { real investment } \\
\text { increase in the } \\
\text { unorganized sector }\end{array}$} & \multicolumn{3}{|c|}{$\begin{array}{l}\text { Wage } \\
10 \% \text { nominal wage } \\
\text { increase inthe } \\
\text { organized sector }\end{array}$} & \multicolumn{3}{|c|}{$\begin{array}{l}\text { Exchange rate } \\
10 \% \text { nominal } \\
\text { exchange } \\
\text { depreciation (rise) }\end{array}$} \\
\hline & 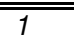 & $\overline{20}$ & 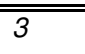 & 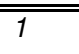 & 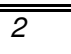 & 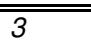 & 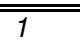 & $\overline{20}$ & 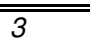 & 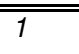 & $\overline{20}$ & 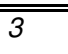 \\
\hline & & & & & & & & & & & & \\
\hline Real GDP growth & 1.1 & 1.2 & 1.3 & 1.4 & 1.4 & 1.5 & -1.0 & -1.0 & -3.0 & -2.8 & -2.9 & 0.1 \\
\hline Inflation & 0.6 & 0.1 & 0.1 & 0.9 & 0.4 & 0.4 & 4.6 & 5.2 & 5.3 & -1.0 & 0.2 & 0.1 \\
\hline Real exchange rate & -0.6 & -0.1 & -0.1 & -0.9 & -0.4 & -0.4 & -4.4 & -4.9 & -5.1 & 11.1 & 9.8 & 9.9 \\
\hline Private balance ( $\Delta$ in $\%$ pts of GDP) & -0.6 & -0.7 & -0.6 & -0.7 & -0.7 & -0.7 & 0.5 & 0.5 & 0.0 & -0.8 & -0.7 & 0.1 \\
\hline Public balance ( $\Delta$ in $\%$ pts of GDP) & 0.4 & 0.3 & 0.3 & 0.4 & 0.4 & 0.4 & 0.5 & 0.5 & 0.1 & -0.7 & -0.6 & 0.1 \\
\hline External balance ( $\Delta$ in $\%$ pts of GDP) & -0.3 & -0.4 & -0.3 & -0.3 & -0.4 & -0.3 & 1.0 & 1.1 & 0.1 & -1.5 & -1.3 & 0.2 \\
\hline Employment share of organized sec ( $\Delta$ in \% pts) & 0.3 & 0.1 & 0.2 & 0.2 & 0.1 & 0.1 & -0.2 & -0.1 & -0.4 & -0.6 & -0.3 & 0.1 \\
\hline Output share of organized $\sec (\Delta$ in $\%$ pts $)$ & 0.3 & 0.3 & 0.4 & -0.1 & -0.1 & -0.1 & -0.3 & -0.3 & -0.9 & -0.4 & -0.5 & 0.3 \\
\hline $\begin{array}{l}\text { Productivity } \\
\text { Organized \& unorganized }\end{array}$ & & & & & & & & & & & & \\
\hline Labor productivity growth - organized & 0.0 & 0.9 & 1.0 & 0.0 & 0.6 & 0.7 & 0.0 & -0.9 & -2.5 & 0.0 & -2.0 & 0.4 \\
\hline $\begin{array}{l}\text { Labor productivity growth - unorganized } \\
\text { Agriculture }\end{array}$ & 0.0 & 0.2 & 0.2 & 0.0 & 0.5 & 0.5 & 0.0 & -0.1 & -0.4 & 0.0 & -0.6 & -0.2 \\
\hline Labor productivity growth & 0.8 & 0.5 & 0.6 & 1.3 & 1.0 & 1.0 & -0.7 & -0.5 & -1.3 & -2.3 & -1.7 & -0.3 \\
\hline Key parameters & 1 & 2 & 3 & & & & & & & & & \\
\hline Trade price elasticities in the organized sector & 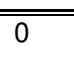 & 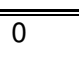 & 0.75 & & & & & & & & & \\
\hline Trade price elasticities in the unorganized sector & 0 & 0 & 0.30 & & & & & & & & & \\
\hline Kaldor-Verdoorn elasticity organized & 0 & 0.50 & 0.50 & & & & & & & & & \\
\hline Kaldor-Verdoorn elasticity unorganized & 0 & 0.20 & 0.20 & & & & & & & & & \\
\hline
\end{tabular}

Table 2: Simulation results (3-sector model). The simulations results are based on a three-sector model for India using data from a Social Accounting Matrix or 2003-04. Four shocks are applied in the context of three different calibrations of key parameters. These parameters and the values they take in each calibration are presented in the lower part of the table. 
(a.1) Real GDP growth: Exchange rate shock

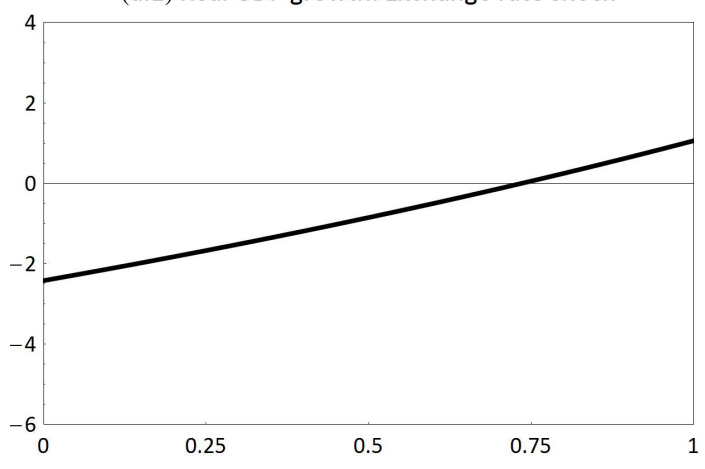

(b.1) Real GDP growth: Demand (o) shock

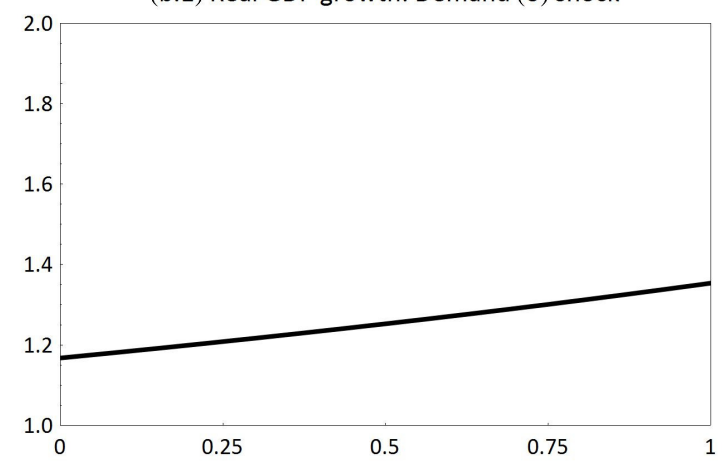

(c.1) Real GDP growth: Demand (u) shock

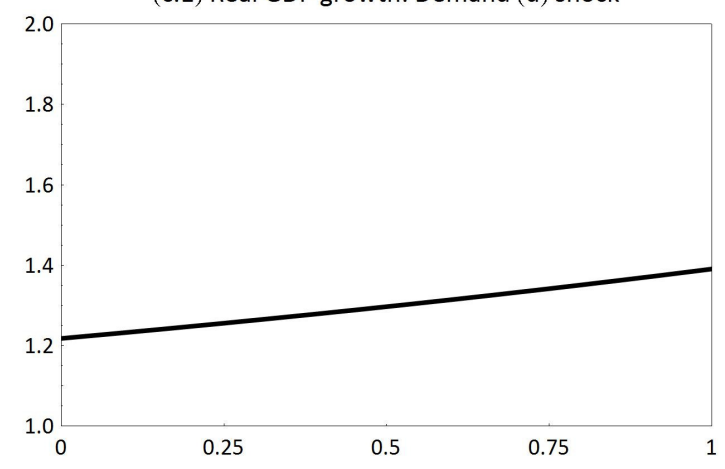

(a.2) Organized employment growth: Exchange rate shock

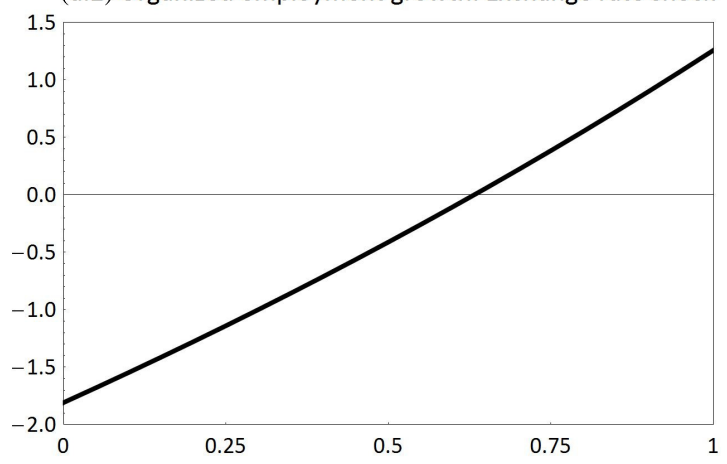

(b.2) Organized employment growth: Demand (o) shock

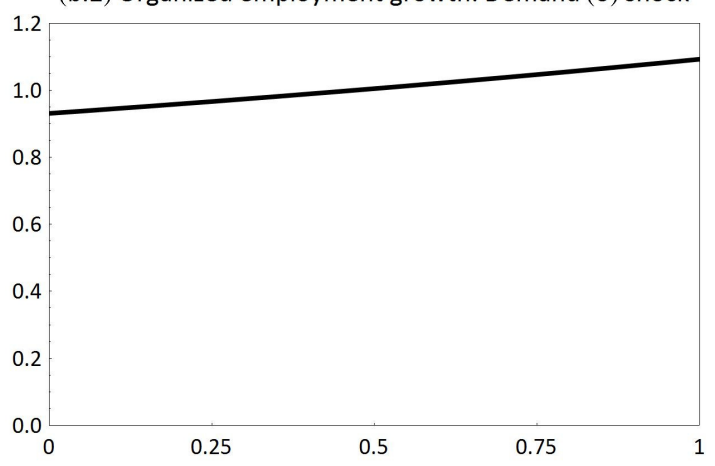

(c.2) Organized employment growth: Demand (u) shock

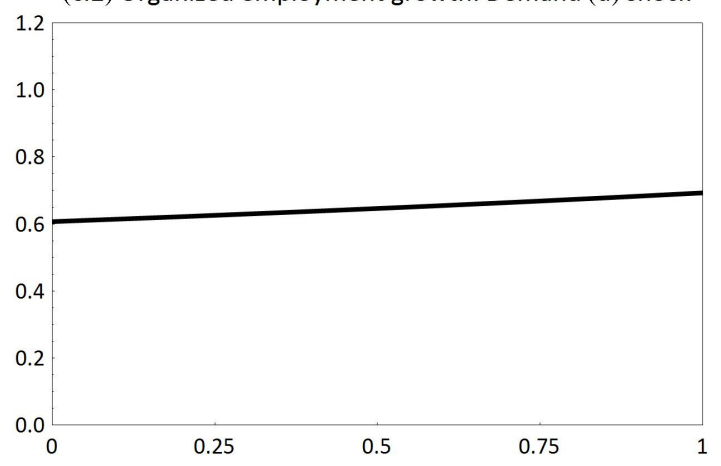

Figure 2: Sensitivity analysis on trade elasticities for the organized sector. 
(a.1.u) Real GDP growth: Exchange rate shock

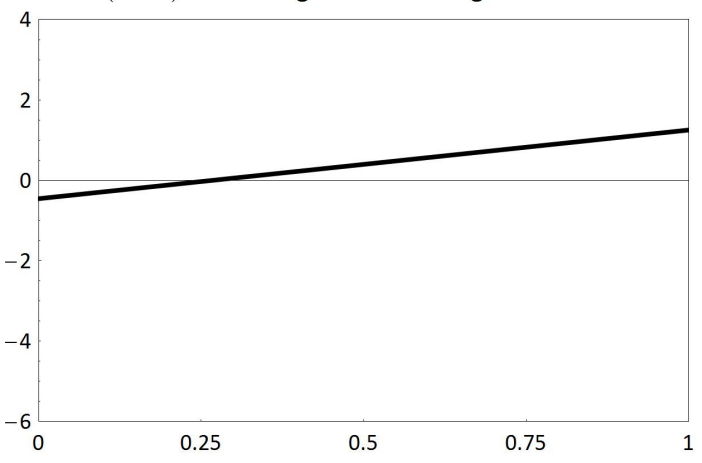

(b.1.u) Real GDP growth: Demand (o) shock

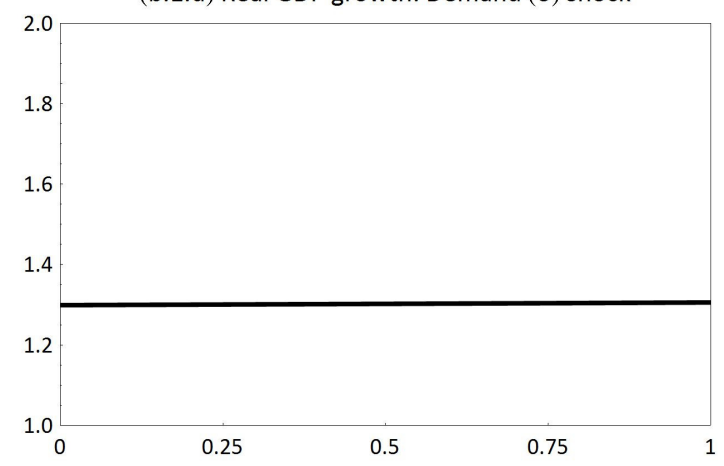

(c.1.u) Real GDP growth: Demand (u) shock

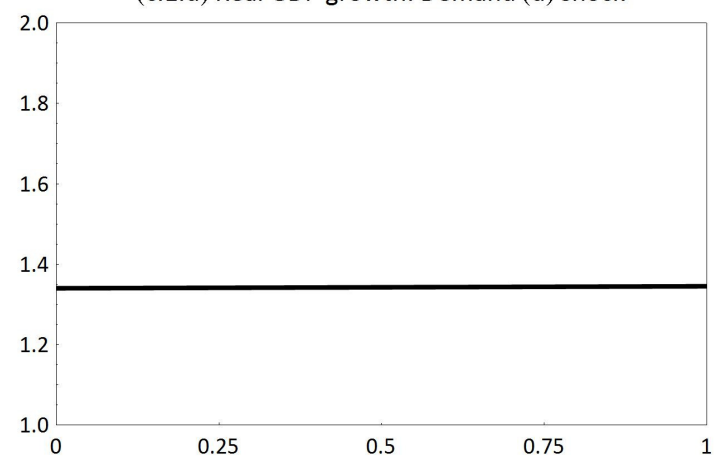

(a.2.u) Organized employment growth: Exchange rate shock

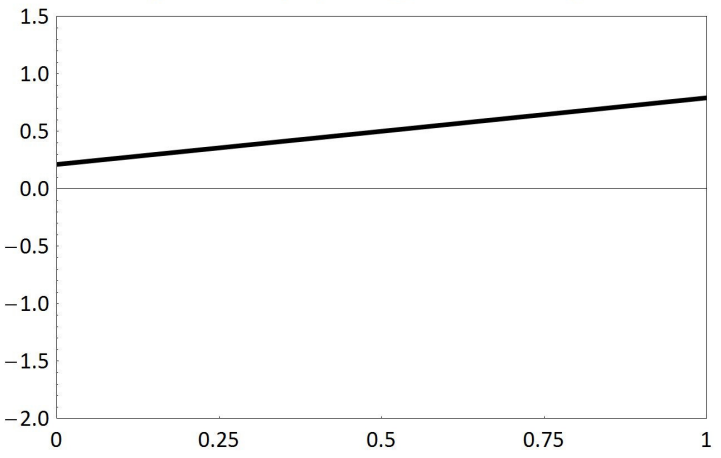

(b.2.u) Organized employment growth: Demand (o) shock

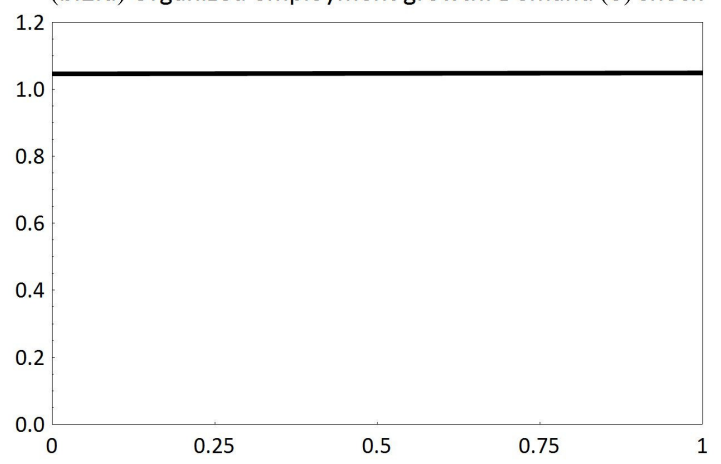

(c.2.u) Organized employment growth: Demand (u) shock

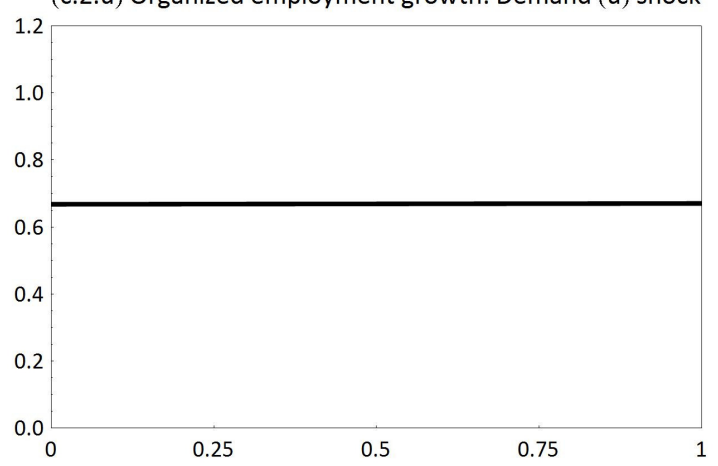

Figure 3: Sensitivity analysis on trade elasticities for the unorganized sectors (it includes agriculture). 

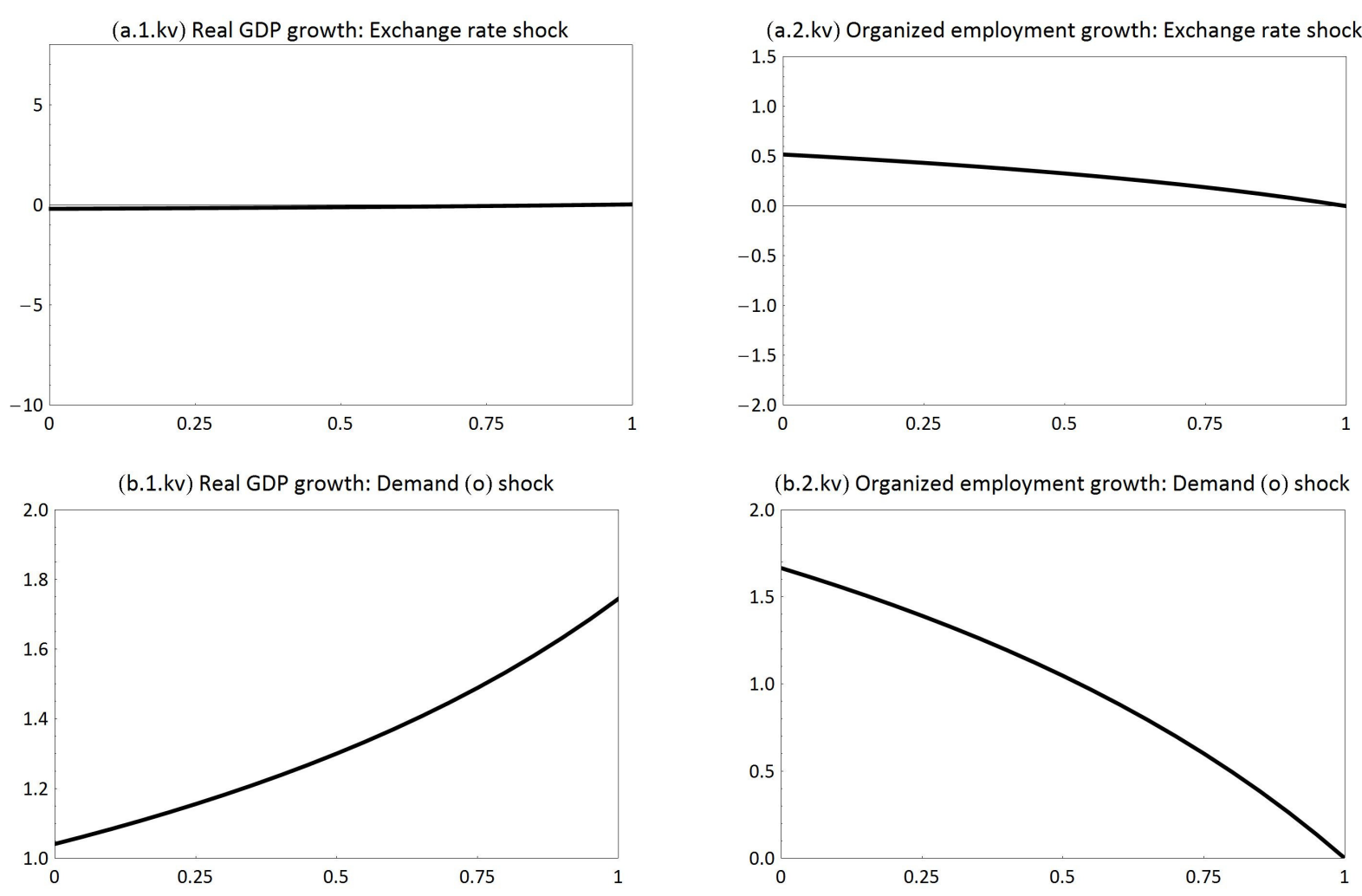

(b.2.kv) Organized employment growth: Demand (o) shock

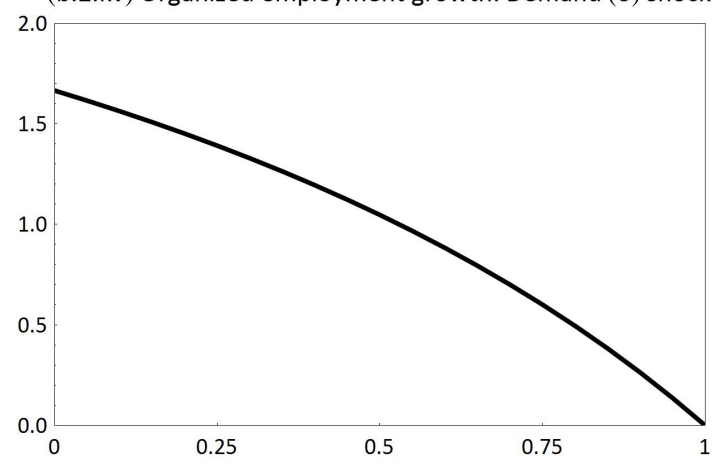

(c.1.kv) Real GDP growth: Demand (u) shock

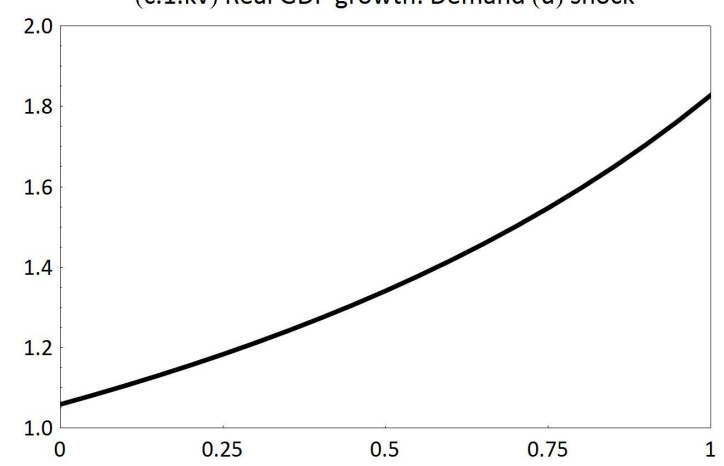

(c.2.kv) Organized employment growth: Demand (u) shock

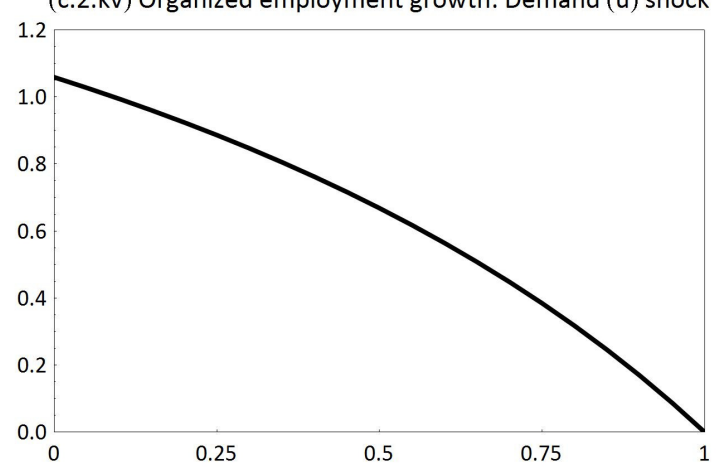

Figure 4: Sensitivity analysis on Kaldor-Verdoorn coefficient for the organized sectors. 
(a.1.kvu) Real GDP growth: Exchange rate shock

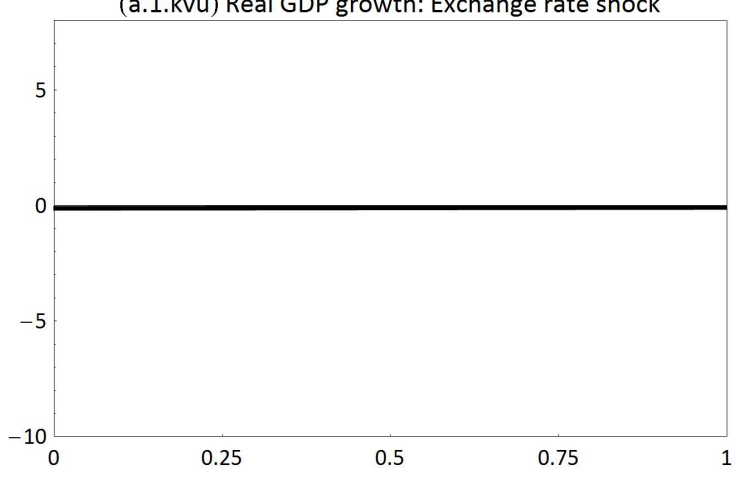

(b.1.kvu) Real GDP growth: Demand (o) shock

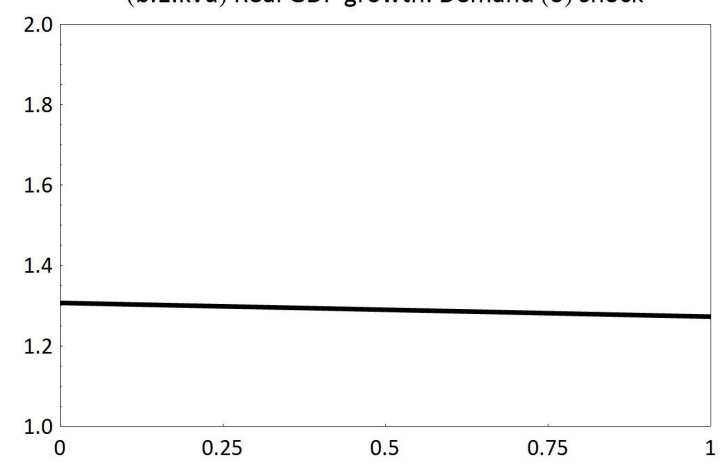

(c.1.kvu) Real GDP growth: Demand (u) shock

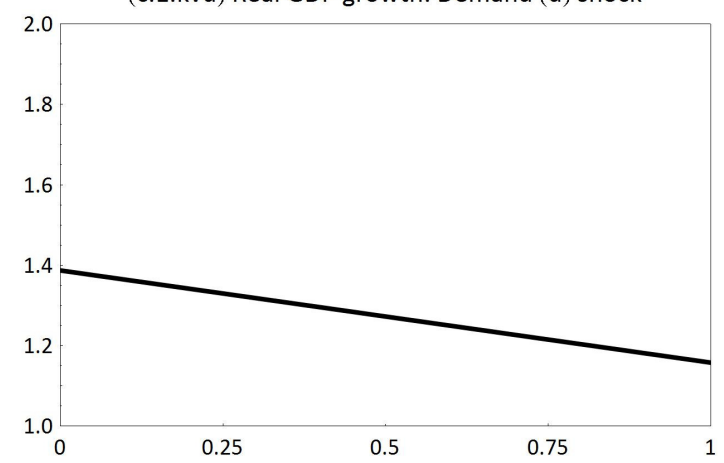

(a.2.kvu) Organized employment growth: Exchange rate shock

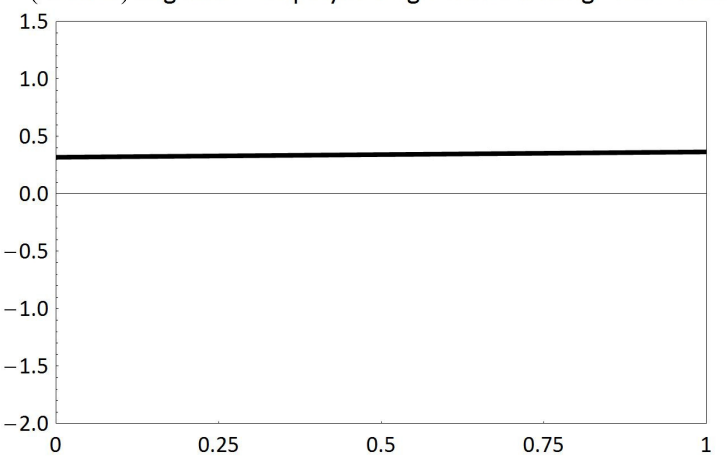

(b.2.kvu) Organized employment growth: Demand (o) shock

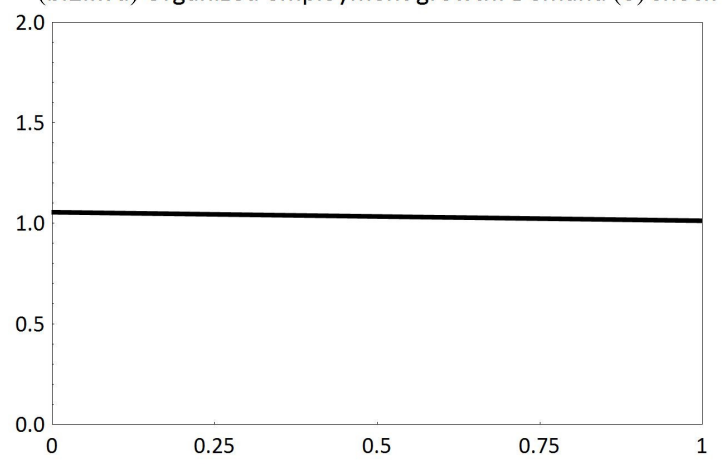

(c.2.kvu) Organized employment growth: Demand (u) shock

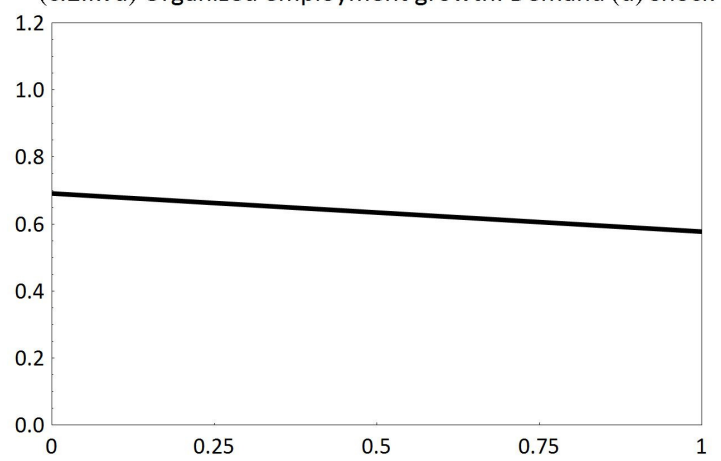

Figure 5: Sensitivity analysis on Kaldor-Verdoorn coefficient for the unorganized sectors (it includes agriculture). 


$$
\begin{aligned}
& P_{i}=\left[1-\sum_{j=1}^{n} m_{i j}\right] Q_{i}+\sum_{j=1}^{n} m_{i j} e_{i j} P_{j} \\
& Q_{i}=\left[1+\tau_{i}\right] \frac{w}{\xi}=\frac{1}{1-\pi_{i}} \frac{w_{i}}{\xi_{i}} \\
& w_{i}=w_{i 0}\left[\frac{L}{N}\right]^{w_{i 1}} \xi w_{i 2} \\
& r_{i}=\pi_{i} \frac{Q_{i} Y_{i}}{P_{i} K_{i}} \\
& \pi_{i}=1-\frac{w_{i} L_{i}}{Q_{i} Y_{i}}=1-\frac{\omega_{i}}{\xi_{i}} \\
& e_{i}=\sum_{j=1}^{n} t_{i j} e_{i j} \\
& \rho_{i}=\sum_{j=1}^{n} t_{i j} e_{i j} \frac{P_{j}}{P_{i}} \\
& X_{i}=C_{i}+I_{i}+G_{i}+E_{i} \\
& C_{i}=\left(1-s_{i}-t x_{i}\right) Q_{i} Y_{i} / P_{i} \\
& Y_{i}=k_{i}\left(I_{i}+G_{i}+E_{i}\right) \\
& k_{i}=\frac{1-\sum_{j=1}^{n} m_{i j}}{1-\left(1-\sum_{j=1}^{n} m_{i j}\right)\left(1-s_{i}-t x_{i}\right) Q_{i} / P_{i}} \\
& M_{i}=\sum_{j=1}^{n} m_{i j} X_{i}=\sum_{j=1}^{n} m_{i 0} \rho_{i j}^{-\alpha_{i j}} X_{i}^{\beta_{i j}} \\
& E_{i}=\sum_{j=1}^{n} m_{j i} X_{j} \\
& t_{i j}=\frac{P_{i} m_{j i} X_{j}+e_{i j} P_{j} m_{i j} X_{i}}{P_{i} \sum_{j=1}^{n} m_{j i} X_{j}+\sum_{j=1}^{n} e_{i j} P_{j} m_{i j} X_{i}} \\
& S_{i}=s_{i} Q_{i} Y_{i}=\left[s_{i \pi}-\left(s_{i \pi}-s_{i \psi}\right)\left(1-\pi_{i}\right)\right] Q_{i} Y_{i} \\
& S_{i g}=t x_{i} Q_{i} Y_{i}-P_{i} G_{i} \\
& \xi_{i}=\xi_{i 0}\left[\frac{Y_{i}}{K_{i}}\right]^{\xi_{i 1}}\left[\frac{W_{i}}{Q_{i}}\right]^{\xi_{i 2}} \\
& L_{i}=\frac{Y_{i}}{\xi_{i}} \\
& C A_{i}=P_{i} \sum_{j=1}^{n} m_{j i} X_{j}-\sum_{j=1}^{n} e_{i j} P_{j} m_{i j} X_{i}=-S_{i f}
\end{aligned}
$$

Table 3: Overview of model equations used for simulations. The model is identical to the one used in von Arnim (2011). 


\begin{tabular}{|c|c|c|c|c|c|c|c|c|}
\hline & \multirow[b]{2}{*}{ Direct } & \multicolumn{3}{|c|}{ Backward } & \multicolumn{4}{|l|}{ Forward } \\
\hline & & Indirect & Average & Direct & Indirect & Average & TOTAL & Classification \\
\hline EUROPE & 1.67 & 2.85 & 2.26 & 1.45 & 4.11 & 2.78 & 5.04 & Very strong \\
\hline US & 1.61 & 2.02 & 1.82 & 0.66 & 2.12 & 1.39 & 3.21 & Very strong \\
\hline ASIA & 0.88 & 0.23 & 0.56 & 0.81 & 0.03 & 0.42 & 0.97 & Strong \\
\hline ENERGY & 0.32 & -0.24 & 0.04 & 0.88 & -0.39 & 0.25 & 0.29 & Strong \\
\hline CHINA & -0.02 & 0.02 & 0.00 & 0.53 & -0.10 & 0.21 & 0.21 & Weak \\
\hline JAPAN & -0.22 & 0.04 & -0.09 & -0.02 & -0.14 & -0.08 & -0.17 & Weak \\
\hline LAC & -0.26 & -0.46 & -0.36 & -0.30 & -0.64 & -0.47 & -0.83 & Weak \\
\hline CANADA & -0.43 & -0.64 & -0.54 & -0.43 & -0.78 & -0.60 & -1.14 & Very weak \\
\hline RUSSIA & -0.52 & -0.63 & -0.58 & -0.40 & -0.76 & -0.58 & -1.16 & Very weak \\
\hline BRAZIL & -0.68 & -0.67 & -0.67 & -0.72 & -0.77 & -0.74 & -1.42 & Very weak \\
\hline INDIA & -0.69 & -0.72 & -0.70 & -0.72 & -0.81 & -0.77 & -1.47 & Very weak \\
\hline AFRICA & -0.81 & -0.86 & -0.84 & -0.85 & -0.91 & -0.88 & -1.72 & Very weak \\
\hline $\begin{array}{l}\text { S. } \\
\text { AFRICA }\end{array}$ & -0.86 & -0.93 & -0.89 & -0.89 & -0.96 & -0.92 & -1.82 & Very weak \\
\hline
\end{tabular}

Table 4: Trade linkages in the world economy. Direct backward (forward) linkages are column (row) sums of the trade flow matrix divided by column (row) country. Indirect backward (forward) linkages are column (row) sums $(\boldsymbol{I}-\boldsymbol{M})^{\mathbf{- 1}}$, where $\boldsymbol{I}$ is the identity matrix and $\boldsymbol{M}$ the trade flow matrix scaled by column (i.e. importing) country. Direct and indirect linkages are weighted by country GDP (relative to US GDP), and then normalized around zero: A positive and high value indicates existing and strong linkages. BRIC countries are highlighted in grey.

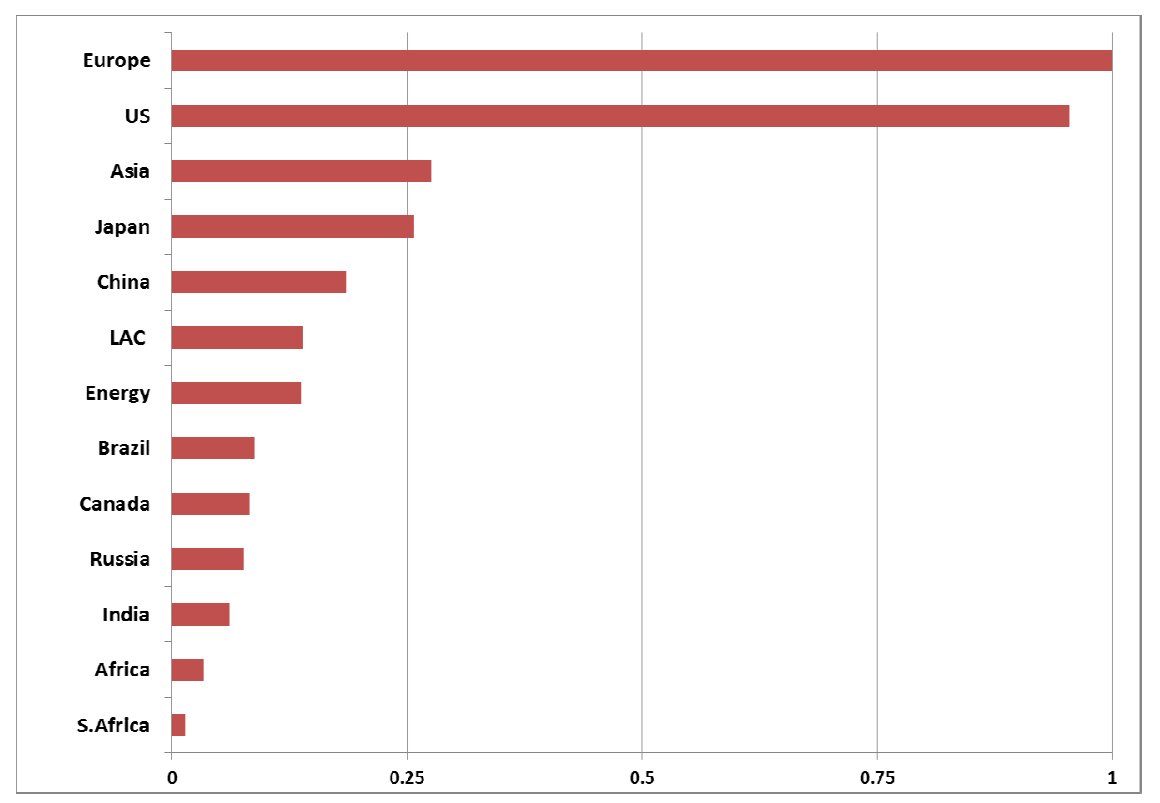

Figure 6: Simulation results. This chart summarizes model results in response to a one-percent-of-GDP investment shock in each respective region or country. The statistic considered here is global real GDP growth (top left cell in the tables above), indexed by Europe's result. As an example, consider Japan: A positive investment demand shock of $1 \%$ of Japan's GDP in Japan leads to global real GDP growth roughly one quarter as strong as a positive investment demand shock of $1 \%$ of Europe's GDP in Europe. 


\begin{tabular}{l||ccccccccc} 
BRIC growth & GDP & w/Q & Y/L & $\mathbf{P}$ & RER & u & Priv & Pub & Ext \\
\hline \hline World & 0.31 & 0.26 & 0.25 & 0.00 & & -0.06 & -0.05 & 0.06 & 0.01 \\
Developed countries & 0.09 & 0.06 & 0.09 & -0.02 & 0.02 & 0.00 & 0.02 & 0.02 & 0.04 \\
Developing countries & 0.83 & 0.72 & 0.64 & 0.04 & -0.03 & -0.18 & -0.27 & 0.15 & -0.12 \\
Excl. BRICS & 0.29 & 0.43 & 0.29 & -0.11 & 0.13 & 0.01 & 0.05 & 0.04 & 0.08 \\
BRICS & 1.28 & 0.96 & 0.92 & 0.17 & -0.17 & -0.33 & -0.56 & 0.23 & -0.33 \\
Brazil & 1.54 & 0.92 & 0.97 & 0.49 & -0.50 & -0.53 & -0.69 & 0.35 & -0.34 \\
Russia & 1.33 & 1.11 & 0.99 & 0.05 & -0.05 & -0.31 & -0.70 & 0.28 & -0.42 \\
India & 1.25 & 0.71 & 0.77 & 0.41 & -0.42 & -0.44 & -0.53 & 0.20 & -0.33 \\
China & 1.25 & 1.04 & 0.98 & 0.04 & -0.03 & -0.25 & -0.49 & 0.20 & -0.30 \\
South Africa & 0.05 & 0.12 & -0.03 & 0.09 & -0.14 & -0.06 & 0.01 & 0.02 & 0.03 \\
& & & & & & & & &
\end{tabular}

Table 5: Simulation results. The first five columns report growth rates of real GDP, real wage, labor productivity, output prices and the real exchange rate. The following four columns report changes in rates: The change in the unemployment rate, and the change in the share of private, public and external balance relative to GDP.This table summarizes model results in response to an investment expansion in the four BRIC countries. In each BRIC country, investment is increased by $1 \%$ of GDP.

\begin{tabular}{l||ccccccccc} 
US, Europe, Japan growth & GDP & w/Q & Y/L & $\mathbf{P}$ & RER & u & Priv & Pub & Ext \\
\hline World & 1.68 & 1.40 & 1.25 & 0.08 & & -0.40 & -0.39 & 0.35 & -0.04 \\
Developed countries & 2.16 & 1.79 & 1.61 & 0.10 & -0.01 & -0.52 & -0.60 & 0.48 & -0.13 \\
Developing countries & 0.71 & 0.65 & 0.56 & 0.02 & 0.07 & -0.14 & 0.18 & 0.11 & 0.30 \\
Excl. BRICS & 0.86 & 0.87 & 0.70 & -0.04 & 0.12 & -0.15 & 0.18 & 0.12 & 0.30 \\
BRICS & 0.59 & 0.47 & 0.45 & 0.06 & 0.03 & -0.13 & 0.19 & 0.11 & 0.30 \\
Brazil & 0.39 & 0.24 & 0.24 & 0.14 & -0.06 & -0.14 & 0.07 & 0.09 & 0.16 \\
Russia & 0.87 & 0.73 & 0.65 & 0.05 & 0.07 & -0.20 & 0.19 & 0.18 & 0.37 \\
India & 0.35 & 0.18 & 0.21 & 0.15 & -0.06 & -0.13 & 0.13 & 0.06 & 0.18 \\
China & 0.62 & 0.52 & 0.52 & 0.01 & 0.08 & -0.09 & 0.25 & 0.10 & 0.34 \\
South Africa & 0.62 & 0.58 & 0.38 & 0.17 & -0.11 & -0.19 & 0.12 & 0.16 & 0.29 \\
& & & & & & & & &
\end{tabular}

Table 6: Simulation results. The first five columns report growth rates of real GDP, real wage, labor productivity, output prices and the real exchange rate. The following four columns report changes in rates: The change in the unemployment rate, and the change in the share of private, public and external balance relative to GDP.This table summarizes model results in response to an investment expansion in developed countries (US, Europe, Japan). In each country, investment is increased by $1 \%$ of GDP. 


\begin{tabular}{l||cccccccccc} 
Brazil growth & GDP & w/Q & Y/L & $\mathbf{P}$ & RER & $\mathbf{u}$ & Priv & Pub & Ext \\
\hline World & 0.07 & 0.07 & 0.08 & -0.03 & & 0.01 & -0.02 & 0.01 & 0.00 \\
Developed countries & 0.01 & -0.01 & 0.03 & -0.03 & 0.00 & 0.02 & 0.00 & 0.00 & 0.01 \\
Developing countries & 0.20 & 0.23 & 0.19 & -0.03 & 0.01 & 0.00 & -0.06 & 0.04 & -0.02 \\
Excl. BRICS & 0.14 & 0.31 & 0.19 & -0.14 & 0.12 & 0.05 & 0.01 & 0.02 & 0.03 \\
BRICS & 0.25 & 0.16 & 0.19 & 0.06 & -0.09 & -0.05 & -0.12 & 0.05 & -0.07 \\
Brazil & 1.46 & 0.87 & 0.92 & 0.46 & -0.50 & -0.50 & -0.71 & 0.34 & -0.37 \\
Russia & 0.01 & 0.00 & 0.02 & -0.01 & -0.01 & 0.01 & 0.00 & 0.00 & 0.01 \\
India & -0.01 & -0.02 & -0.02 & 0.01 & -0.06 & -0.01 & 0.00 & 0.00 & 0.00 \\
China & 0.02 & 0.03 & 0.08 & -0.04 & 0.02 & 0.06 & 0.02 & 0.00 & 0.02 \\
South Africa & -0.10 & 0.01 & -0.13 & 0.07 & -0.16 & -0.03 & -0.02 & -0.01 & -0.03
\end{tabular}

Table 7: Simulation results. The first five columns report growth rates of real GDP, real wage, labor productivity, output prices and the real exchange rate. The following four columns report changes in rates: The change in the unemployment rate, and the change in the share of private, public and external balance relative to GDP.This table summarizes model results in response to an investment expansion of 1\% of GDP in Brazil.

\begin{tabular}{l||cccccccccc} 
Russia growth & GDP & w/Q & Y/L & $\mathbf{P}$ & RER & u & Priv & Pub & Ext \\
\hline \hline World & 0.06 & 0.07 & 0.07 & -0.04 & & 0.02 & -0.01 & 0.01 & 0.01 \\
Developed countries & 0.01 & -0.01 & 0.03 & -0.03 & -0.01 & 0.02 & 0.01 & 0.00 & 0.01 \\
Developing countries & 0.17 & 0.24 & 0.18 & -0.07 & 0.03 & 0.01 & -0.06 & 0.04 & -0.02 \\
Excl. BRICS & 0.12 & 0.30 & 0.17 & -0.14 & 0.11 & 0.05 & 0.01 & 0.01 & 0.02 \\
BRICS & 0.22 & 0.19 & 0.19 & -0.01 & -0.03 & -0.02 & -0.12 & 0.06 & -0.07 \\
Brazil & 0.00 & 0.01 & -0.01 & 0.00 & -0.05 & -0.01 & 0.00 & 0.00 & 0.00 \\
Russia & 1.23 & 1.03 & 0.92 & 0.04 & -0.07 & -0.29 & -0.72 & 0.26 & -0.45 \\
India & -0.02 & -0.03 & -0.03 & 0.01 & -0.07 & -0.01 & 0.00 & 0.00 & 0.00 \\
China & 0.02 & 0.03 & 0.09 & -0.05 & 0.01 & 0.06 & 0.02 & 0.00 & 0.02 \\
South Africa & -0.11 & 0.00 & -0.14 & 0.06 & -0.17 & -0.03 & -0.02 & -0.01 & -0.03
\end{tabular}

Table 8: Simulation results. The first five columns report growth rates of real GDP, real wage, labor productivity, output prices and the real exchange rate. The following four columns report changes in rates: The change in the unemployment rate, and the change in the share of private, public and external balance relative to GDP.This table summarizes model results in response to an investment expansion of $1 \%$ of GDP in Russia. 


\begin{tabular}{l||ccccccccc} 
India growth & GDP & w/Q & Y/L & $\mathbf{P}$ & RER & $\mathbf{u}$ & Priv & Pub & Ext \\
\hline \hline World & 0.05 & 0.05 & 0.06 & -0.03 & & 0.02 & -0.01 & 0.01 & 0.00 \\
Developed countries & 0.00 & -0.01 & 0.02 & -0.03 & 0.00 & 0.02 & 0.00 & 0.00 & 0.00 \\
Developing countries & 0.15 & 0.19 & 0.16 & -0.05 & 0.02 & 0.01 & -0.03 & 0.02 & -0.02 \\
Excl. BRICS & 0.13 & 0.30 & 0.18 & -0.14 & 0.11 & 0.05 & 0.01 & 0.02 & 0.02 \\
BRICS & 0.16 & 0.11 & 0.14 & 0.03 & -0.06 & -0.02 & -0.07 & 0.02 & -0.06 \\
Brazil & -0.01 & 0.00 & -0.02 & 0.00 & -0.04 & -0.01 & 0.00 & 0.00 & 0.00 \\
Russia & 0.01 & 0.00 & 0.02 & -0.02 & -0.01 & 0.01 & 0.00 & 0.00 & 0.00 \\
India & 1.16 & 0.66 & 0.72 & 0.38 & -0.43 & -0.41 & -0.56 & 0.19 & -0.37 \\
China & 0.02 & 0.03 & 0.08 & -0.05 & 0.02 & 0.06 & 0.02 & 0.00 & 0.02 \\
South Africa & -0.08 & 0.02 & -0.12 & 0.07 & -0.16 & -0.03 & -0.01 & -0.01 & -0.02
\end{tabular}

Table 9: Simulation results. The first five columns report growth rates of real GDP, real wage, labor productivity, output prices and the real exchange rate. The following four columns report changes in rates: The change in the unemployment rate, and the change in the share of private, public and external balance relative to GDP.This table summarizes model results in response to an investment expansion of $1 \%$ of GDP in India.

\begin{tabular}{l||ccccccccc} 
China growth & GDP & w/Q & Y/L & $\mathbf{P}$ & RER & u & Priv & Pub & Ext \\
\hline \hline World & 0.14 & 0.14 & 0.13 & -0.03 & & -0.01 & -0.01 & 0.03 & 0.01 \\
Developed countries & 0.03 & 0.01 & 0.04 & -0.02 & 0.00 & 0.01 & 0.01 & 0.01 & 0.01 \\
Developing countries & 0.41 & 0.43 & 0.36 & -0.05 & 0.02 & -0.06 & -0.11 & 0.07 & -0.05 \\
Excl. BRICS & 0.19 & 0.35 & 0.22 & -0.13 & 0.11 & 0.04 & 0.02 & 0.02 & 0.05 \\
BRICS & 0.60 & 0.50 & 0.47 & 0.02 & -0.05 & -0.13 & -0.24 & 0.10 & -0.14 \\
Brazil & 0.03 & 0.03 & 0.01 & 0.01 & -0.05 & -0.02 & 0.01 & 0.01 & 0.01 \\
Russia & 0.04 & 0.03 & 0.04 & -0.01 & 0.00 & 0.01 & 0.01 & 0.01 & 0.02 \\
India & 0.01 & -0.02 & -0.01 & 0.02 & -0.07 & -0.02 & 0.01 & 0.00 & 0.01 \\
China & 1.16 & 0.97 & 0.92 & 0.03 & -0.06 & -0.23 & -0.52 & 0.19 & -0.34 \\
South Africa & -0.05 & 0.04 & -0.10 & 0.07 & -0.16 & -0.04 & -0.01 & 0.00 & -0.01 \\
& & & & & & & & &
\end{tabular}

Table 10: Simulation results. The first five columns report growth rates of real GDP, real wage, labor productivity, output prices and the real exchange rate. The following four columns report changes in rates: The change in the unemployment rate, and the change in the share of private, public and external balance relative to GDP.This table summarizes model results in response to an investment expansion of $1 \%$ of GDP in India. 